\title{
Challenges of in-vacuum and cryogenic permanent magnet undulator technologies
}

\author{
Jui-Che Huang, ${ }^{1 *}$ Hideo Kitamura, ${ }^{2}$ Chin-Kang Yang, ${ }^{1}$ Cheng-Hsing Chang, ${ }^{1}$ \\ Cheng-Hsiang Chang, ${ }^{1}$ and Ching-Shiang Hwang ${ }^{1}$ \\ ${ }^{1}$ National Synchrotron Radiation Research Center, Hsinchu Science Park, Hsinchu 30073, Taiwan \\ ${ }^{2}$ RIKEN SPring-8 Center, 1-1-1 Kouto, Mikazuki-cho, Sayo-gun, Hyogo 679-5148, Japan
}

(Received 30 December 2016; published 29 June 2017)

\begin{abstract}
An in-vacuum undulator (IVU) provides a means to reach high-brilliance $\mathrm{x}$ rays in medium energy storage rings. The development of short period undulators with low phase errors creates the opportunity for an unprecedented brilliant light source in a storage ring. Since the spectral quality from cryogenic permanent magnet undulators (CPMUs) has surpassed that of IVUs, NdFeB or PrFeB CPMUs have been proposed for many new advanced storage rings to reach high brilliance x-ray photon beams. In a low emittance ring, not only the performance of the undulator but also the choice of the lattice functions are important design considerations. Optimum betatron functions and a zero-dispersion function shall be provided in the straight sections for IVU/CPMUs. In this paper, relevant factors and design issues for IVUs and CPMUs are discussed together with many technological challenges in short period undulators associated with beam induced-heat load, phase errors, and the deformation of support girders.
\end{abstract}

DOI: 10.1103/PhysRevAccelBeams.20.064801

\section{INTRODUCTION}

Undulators are the main insertion devices to generate high brightness radiation in synchrotron radiation (SR) facilities. There are two ways to obtain short wavelength undulator radiation, one is to use a short-period undulator while the other is to increase the electron beam energy to expand the spectrum to higher energies. Compared to the second approach, a short period undulator seems to be a more cost-effective option, because it allows a lower beam energy and smaller size of the facility. Moreover, a higher photon flux is obtained because the number of periods can be made larger for an undulator within the available space. Therefore, short period undulators have become the preferred design solutions in the development of insertion devices.

The shortest period length is limited by the required aperture for the electron beam and desired magnetic field strength. In an in-vacuum undulator (IVU), the entire magnetic gap is available. Its development has begun with the construction and use of the first IVU at the NSLS VUV ring in 1983 [1]. This device was, though, removed soon after installation for its vacuum problems. In 1986, an undulator with a unique structure was developed [2] at BESSY. The magnet array was encapsulated in its own vacuum chamber separated from the ring vacuum. This design had some advantages compared to earlier undulators,

\footnotetext{
*huang.juiche@nsrrc.org.tw
}

Published by the American Physical Society under the terms of the Creative Commons Attribution 4.0 International license. Further distribution of this work must maintain attribution to the author(s) and the published article's title, journal citation, and DOI. the vacuum gap was variable by varying the separate chamber aperture together with the magnetic gap. However, the thickness of the separate vacuum chamber could not be made thinner than $2 \mathrm{~mm}$ which caused a loss in effective magnetic gap of $4 \mathrm{~mm}$. Such a loss, the difference between the magnetic gap and the vacuum gap, is called the gap loss. The first IVU was developed and constructed for routine operation in the $6.5 \mathrm{GeV}$ storage ring at KEK in 1991 [3]. Since then, hundreds of IVUs based on the KEK concept have been installed in various storage rings [4-10] across the world because IVUs allow shorter period lengths and a high field quality. They have become desirable photon sources of hard $\mathrm{x}$ rays for medium energy storage rings by utilizing higher harmonics of undulator radiation. In general, an undulator with high tunability can provide a wide energy spectrum with overlapping harmonics for scientific research in a synchrotron radiation facility. To obtain higher harmonics from an undulator with a short period length $\left(\lambda_{u}\right)$, a strong magnetic field $(B)$ is necessary to reach a deflection parameter $K=0.934 B($ tesla $) \lambda_{u}(\mathrm{~cm})>2$. We call such an undulator a "standard-undulator." At the $8 \mathrm{GeV}$ SPring- 8 storage ring, 16 out of 28 IVUs, all with a period length of $32 \mathrm{~mm}$ and a $K$ value of 2.4, have been operated as standardundulators since 1997. In lower energy storage rings, however, other characteristics like uniform field and lowphase errors become important to reach higher harmonics from standard undulators. Phase errors describe the fluctuation of the phase difference between the electromagnetic wave from an undulator and a reference wave [11]. The imperfection of the magnetic field causes such a fluctuation of the phase difference degrading the desired constructive interference. This specification is important for $3-\mathrm{GeV}$ facilities where the utilization of higher harmonics of undulator radiation is essential to reach hard $\mathrm{x}$ rays. 
In addition, ultrahigh-vacuum (UHV) compatibility, high thermal resistance and high radiation resistance have become important design considerations for advanced standard-undulator designs.

In XFEL facilities, IVUs with a short period length allow decreasing the electron beam energy and accelerator length for a more compact facility size (SACLA [12] and Swiss FEL [13]). In a linac-based FEL, the beam-induced heat load is negligible because no SR exists from an upstream bending magnet and because of a low average beam current; besides, it is not necessary to consider injection issues necessary for storage rings. Therefore, one can adopt an IVU with a narrow pole width corresponding smaller region of the magnetic field uniformity in the transverse direction (also known as "good-field-region"), which means that multipole fields can be less of a concern. In addition, the pressure for IVUs can be higher than $10^{-6} \mathrm{~Pa}$, so the vacuum components need not necessarily be UHV compatible and have high thermal resistance against UHV bakeout. On the other hand, radiation damage issues in linacs become more serious $[14,15]$ compared to storage rings because the electron halo surrounding the particle beam can result in radiation damage of permanent magnet materials. Electron losses from the halo are not always detectable. In storage rings, the electron beam has a Gaussian-like distribution, and beam loss can be monitored precisely by accurate beam lifetime measurements. Considering the resistive wall instability, additional caution is necessary because the typical bunch length in XFEL linacs is typically a hundred times shorter compared to the $10 \mathrm{psec}$ in storage rings. Such short linac bunches may create energy variations in the electron beam through interaction with the narrow undulator vacuum pipe [16]. In order to suppress such effects, the inner surface of the pipe must be very smooth, which means that the inside of the IVU gap must appear smooth to the beam as well. Overall, the technical challenges for IVUs in XFELs are less severe than their use in storage rings. In this paper, the discussion is focused mainly on IVUs in a storage ring.

Superconducting undulators (SCUs) or cryogenic permanent magnet undulators (CPMUs) operating at a low temperature are other potential candidates for advanced standard undulators. The first SCU with a helical structure was developed at the Stanford linac-based FEL in 1976 [17] and was followed by a planar SCU with a period length of $40 \mathrm{~mm}$ installed in Orsay at the storage ring A.C.O. [18] and the demonstration of the first permanent magnet undulator at SSRL-SLAC in 1981 [19]. At present, SCUs provide routinely high-brilliant $\mathrm{x}$ rays in storage rings like, for example, the SCU0 at APS with a period length of $16 \mathrm{~mm}$ and 20.5 periods generating a magnetic field of $0.8 \mathrm{~T}$ at a magnetic/vacuum gap of $9.5 \mathrm{~mm} / 7.2 \mathrm{~mm}$ [20], and the SCU15 at ANKA with a period length of 15 $\mathrm{mm}, 100.5$ periods and a magnetic field of $0.73 \mathrm{~T}$ at a magnetic/vacuum gap of $8 \mathrm{~mm} / 7 \mathrm{~mm}$ [21].
An alternative design option, the CPMU, which can be regarded as an extension of the IVU design, was proposed at SPring-8 in 2004 [22]. Permanent magnets (PMs) in a CPMU are cooled down to cryogenic temperatures (CT) below $150 \mathrm{~K}$ where UHV condition can be achieved due to the low outgassing rate of the PMs and where properties like remanence and coercivity are improved significantly. Early developments of CPMUs have been pursued at SPring-8 [23,24], and the desired magnetic field quality was demonstrated in a $0.6-\mathrm{m} \mathrm{NdFeB-CPMU}$ prototype with a 14-mm period length. The magnetic characteristics of several magnet materials were explored at SPring-8 [22], SOLEIL [25] and HZB [26,27] to characterize the magnetic performance of CPMUs. At ESRF in 2008, a 2-m long CPMU with a period length of $18 \mathrm{~mm}$ was built based on $\mathrm{NdFeB}$ magnets [28] becoming the first full-scale CPMU operating in a storage ring [29,30] followed by other CPMUs operating in storage rings such as SOLEIL [31], DLS [32], SLS [33] and ESRF [34]. A CPMU at ESRF demonstrated that a nonbaked device can operate smoothly in a storage ring [34]. The first full-scale PrFeB-CPMU with a period length of $18 \mathrm{~mm}$ has been designed and operated in the storage ring at SOLEIL [31]. From then on, PrFeB-CPMUs have become the preferred choice for the development of CPMUs because of the higher magnetic field compared to NdFeB-CPMUs.

The CPMU design is an evolution from the IVU, providing higher magnetic fields and a higher resistance against radiation damage. In addition, the spectral performance of CPMUs is superior to that of IVUs in the hard $\mathrm{X}$-ray region. Although the operational cost of a CPMU is comparatively higher than that of an IVU, CPMUs may eventually replace IVUs. In principle, a SCU could generate higher magnetic fields compared to a CPMU at the same magnetic gap, but considering beam-induced heat loads, the practically available field performance of a CPMU is thought to have a high potential while the period length is approaching sub-cm. On the other side, there is some risk of demagnetization due to radiation damage in a CPMU. In summary, an overall advantage of a small gap CPMU or SCU has not yet been established in the development of short period undulators.

In the present paper, we discuss technical challenges for an IVU and CPMU to ensure a stable operation in a storage ring. Low phase error issues and optimal lattice functions for an undulator are discussed to maximize the undulator performance for low emittance storage rings.

\section{IN-VACUUM UNDULATOR TECHNOLOGIES}

\section{A. Design of IVUs and CPMUs}

A typical design of an IVU is illustrated on the left side of Fig. 1. The mechanical frame with high rigidity and gap driving system with small backlash both ensure adequate reproducibility and high accuracy of the gap motion. 


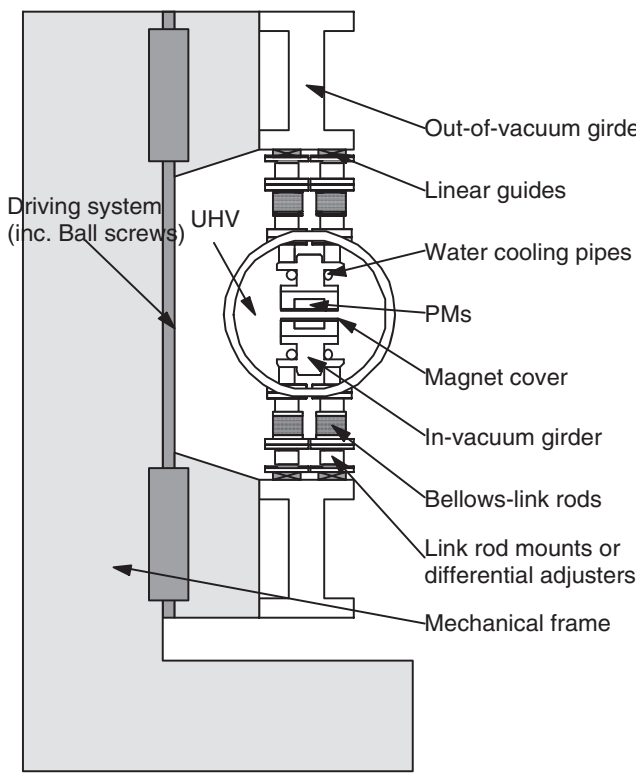

In-Vacuum Undulator

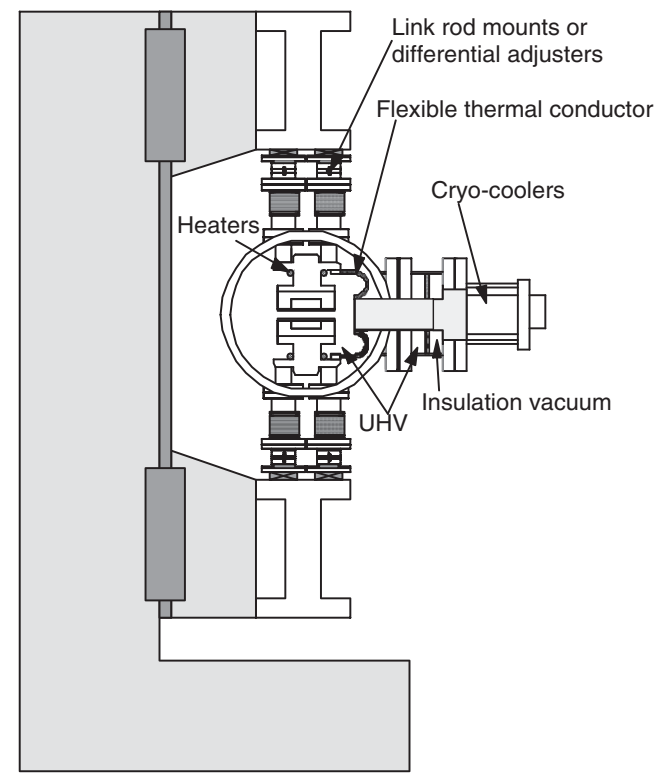

Cryogenic Permanent Magnet Undulator for TPS

FIG. 1. Sketch of an in-vacuum undulator and cryogenic permanent magnet undulator for TPS.

The out-of-vacuum girder is connected to ball screws and moved by a gap driving system. The bellows-link rods transfer the motion from the girder to the magnet arrays which are supported by an in-vacuum girder made of aluminum or oxygen-free-high-conductivity copper (OFHC). Linear guides are located between the link rod mounts and the out-of-vacuum girders, which allow a longitudinal motion of the bellows-link rods during installation. The linear guides also allow movement of the bellows-link rods during high temperature bakeout. The temperature of the cooling water is controlled to $\pm 0.1 \mathrm{C}$, to remove the power derived from direct or indirect synchrotron radiation and image current heating and to maintain close temperature uniformity along the magnet array. An uneven thermal distribution can result in increased phase errors and broadening of the spectral width of the undulator radiation. Several NEG pumps (not shown in the figure) with high pumping speed provide the desired UHV condition, while some ion pumps take care of nongetterable gases.

The right side of Fig. 1 shows a schematic view of a CPMU being developed for the Taiwan Photon Source (TPS), which is based on IVU technologies with the addition of cryocoolers. Such a cooling system can provide a cooling capacity of several hundred watts at liquid nitrogen temperatures (LNT). Separate vacuum chambers for UHV in the CPMU and an insulation vacuum of the cryocooler are required for maintenance purposes. Since cryocoolers are fixed on the vacuum flanges, a flexible thermal conductor between the magnet arrays and the cryocoolers is necessary for a variable undulator gap.
The use of copper straps with high flexibility is proposed for the TPS-CPMU. The heaters are fixed to the in-vacuum girders to maintain a constant temperature of the PMs independent from operational storage ring modes or undulator gap conditions. As an example, the main parameters of the CPMU at TPS are shown in Table I together with parameters of the IVU for comparison.

TABLE I. CPMU and IVU parameters at TPS.

\begin{tabular}{lcc}
\hline \hline Parameter & IU22 (IVU) & CU15 (CPMU) \\
\hline Magnet & NdFeB & PrFeB \\
Period length & $22 \mathrm{~mm}$ & $15 \mathrm{~mm}$ \\
Undulator length & $3 \mathrm{~m}$ & $2 \mathrm{~m}$ \\
Number of periods & 140 & 133 \\
Pole width & $46 \mathrm{~mm}$ & $46 \mathrm{~mm}$ \\
Out-of-vacuum girder & & \\
$\quad$ (steel) & & \\
Second moment of area & $1.84 \times 10^{8} \mathrm{~mm}^{4}$ & $4.18 \times 10^{8} \mathrm{~mm}^{4}$ \\
Young's modulus & $206 \mathrm{GPa}$ & $206 \mathrm{GPa}$ \\
In-vacuum girder (OFHC) & & \\
Second moment of area & $2.15 \times 10^{6} \mathrm{~mm}^{4}$ & $2.15 \times 10^{6} \mathrm{~mm}^{4}$ \\
Young's modulus & $130 \mathrm{GPa}$ & $130 \mathrm{GPa}$ \\
Operating temperature & $300 \mathrm{~K}$ & $<80 \mathrm{~K}$ \\
Total cooler capacity & & $400 \mathrm{~W}$ at $80 \mathrm{~K}$ \\
Minimum magnetic gap & $5 \mathrm{~mm}$ & $3-4 \mathrm{~mm}$ \\
Minimum vacuum gap & $4.8 \mathrm{~mm}$ & $2.8-3.8 \mathrm{~mm}$ \\
Maximum magnetic field & $1.27 \mathrm{~T}$ & $1.77-1.32 \mathrm{~T}$ \\
Maximum $K$ value & 2.61 & $2.48-1.85$ \\
Maximum magnetic force & $34.6 \mathrm{kN}$ & $57.2-31.8 \mathrm{kN}$ \\
\hline \hline
\end{tabular}




\section{B. Permanent magnet with ultrahigh vacuum compatibility}

The first priority in the development of an IVU is to ensure UHV compatibility, because the PMs in an IVU are directly exposed to the storage ring UHV environment. We consider two design approaches of the PMs [35] by, first, selecting a magnet material which is resistant to UHV bakeout. Samarium-cobalt $\left(\mathrm{Sm}_{2} \mathrm{Co}_{17}\right)$ and neodynium-iron-boron $(\mathrm{NdFeB})$ are common PM material for existing in-vacuum undulators. Rare-earth magnets are characterized by the remanence $(B r)$ and intrinsic coercivity $(H c j)$. The magnetic field intensity associated with $\mathrm{Br}$ and $\mathrm{Hcj}$ is a measure of the resistance against demagnetization. $\mathrm{Sm}_{2} \mathrm{Co}_{17}$ has a Curie temperature around $800^{\circ} \mathrm{C}$ and a coercivity of 1700-2000 kA/m, giving $\mathrm{Sm}_{2} \mathrm{Co}_{17}$ the distinguishing property of high temperature stability and high resistance against demagnetization. However, $\mathrm{Sm}_{2} \mathrm{Co}_{17}$ is very brittle and easily produces dust that contaminates the UHV. $\mathrm{NdFeB}$ has higher remanent field/energy values than $\mathrm{Sm}_{2} \mathrm{Co}_{17}$ (1.15-1.42 T/200-440 kJ/m $\mathrm{m}^{3}$ for $\mathrm{NdFeB}$, and $1.05-1.15$ $\mathrm{T} / 150-240 \mathrm{~kJ} / \mathrm{m}^{3}$ for $\mathrm{Sm}_{2} \mathrm{Co}_{17}$ ) [36]. To choose $\mathrm{NdFeB}$ $\mathrm{PM}$ material may force a compromise between remanence and coercivity because high remanent grades have a moderate coercivity and vice versa. For a short period undulator, a high magnetic field is required to obtain a high $K$ value. $\mathrm{NdFeB}$ with high coercivity is therefore preferable to $\mathrm{Sm}_{2} \mathrm{Co}_{17}$ for IVUs. Yet, the choice of $\mathrm{NdFeB}$ must satisfy a coercivity greater than $2000 \mathrm{kA} / \mathrm{m}$ [37] to avoid not only demagnetization at UHV bakeout but also radiation damage. Implementation of Dy diffusion [38]/grain-boundary diffusion [39] technologies in NdFeB PMs allows coercivity enhancements by some $400 \mathrm{kA} / \mathrm{m}$ without sacrificing remanence $[38,39]$.

The second approach is to apply an appropriate coating, $\mathrm{Ni}$ electroplating or TiN ion plating on rare earth PMs, to reduce outgassing from the surface. The coating thickness of TiN ion plating and Ni electroplating is around $5 \mu \mathrm{m}$ and $30-100 \mu \mathrm{m}$, respectively [35]. The former is favorable for short period IVUs because of a smaller gap reduction by the thin coating and hard coat property.

In the early phase of the development at KEK, two strategies were considered to achieve UHV conditions for an IVU. One is a bake-out option (high temperature bakeout of $\mathrm{PMs}$ ) and the other is a nonbakeout option (cooling PMs to CT) [40]. For an IVU, thermal treatment (aging process) of PMs with high coercivity improves the resistance against not only demagnetization during UHV bakeout (flux loss $<0.1 \%$ ) but also against radiation damage [37,41]. In the KEK development, thermal treatment of the PMs was found to make the bakeout option acceptable.

The development of a CPMU is based on this nonbakeout option to achieve UHV conditions. Permanent magnets in a CPMU are operated at CT, therefore, all cold surfaces of PMs together with the in-vacuum girders act as cryopumps [22].

\section{Reduction of impedance}

For bunches of an electron beam passing through the gap of an IVU, the surrounding magnet surfaces shall be smooth with a low electric resistance in the longitudinal direction to reduce the resistive-wall impedance and wakefields. Therefore, special measures to reduce the impedance shall be adopted for an IVU. One of them is a magnet cover (shown in Fig. 1) and the other is a flexible-taper system (Fig. 2) attached at both ends to the in-vacuum girders. A wakefield may be induced by the interaction between electron beams and steps on the surface of the magnet arrays, so the magnet cover serves as a smooth surface on top of the magnet arrays. Without a magnet cover, single bunch instabilities may be excited at a high bunch current [42]. A nickel-plated copper foil is an effective choice as a magnet cover because the copper foil, on one side, has a high electric and adequate thermal conductivity while the nickel layer provides satisfactory attachment to the PMs through the magnetic attractive force. The thickness of the nickel layer must be determined by the beam-induced heat load. A thick nickel layer would provide a strong magnetic force, giving high thermal contact between the PMs and the cover at the expense of a loss of available undulator gap. A suitable thickness for the nickel layer in a storage ring IVU is recommended to be around $50 \mu \mathrm{m}$, but a thinner nickel layer might be possible in an XFEL IVU. The thickness of the copper sheet shall be $50 \mu \mathrm{m}$ to avoid lowfrequency dominant resistive wall instabilities [35]. As a result, the total thickness of the magnet cover is $100 \mu \mathrm{m}$ and the total gap loss is only $0.2 \mathrm{~mm}$.

To decrease the impedance of transition tapers at both ends of an IVU, a flexible transition is connected between the entrance/exit of an undulator vacuum chamber and the IVU gap. The flexible transition must have a displacement allowance for the variation of the gap or thermal expansion during UHV bakeout. A water cooling channel on the flexible taper is essential to remove the heat derived from SR coming from the upstream bending magnet and from image current heating. Various water cooling channel designs for the taper have been pursued so far. A solution with high cooling capacity was developed in a collaboration between SLS and SPring-8 [43]. Figure 2(a) shows a similar type with a cellular-radiator-like structure and reasonable flexibility. One end is fixed on the magnet arrays, and the other is mounted on the vacuum duct with a sliding mechanism. Such a design can prevent unnecessary thermal stress of the transition taper during high temperature bakeout. Another type, adopted at the TPS, has a drawbridge structure using a 6-mm thick OFHC plate [Fig. 2(b)]. The flexibility can be obtained by $\mathrm{BeCu}$ foils located on both ends or by a sliding mechanism in analogy to the SLS type. Observations at TPS IVUs show a temperature rise of 2.5 degrees $\mathrm{C}$ from image current heating of $1 \mathrm{~W}$ at a beam current of $400 \mathrm{~mA}$ with an IVU gap of $7 \mathrm{~mm}$. A cooling capacity of some $10 \mathrm{~W}$ for an 


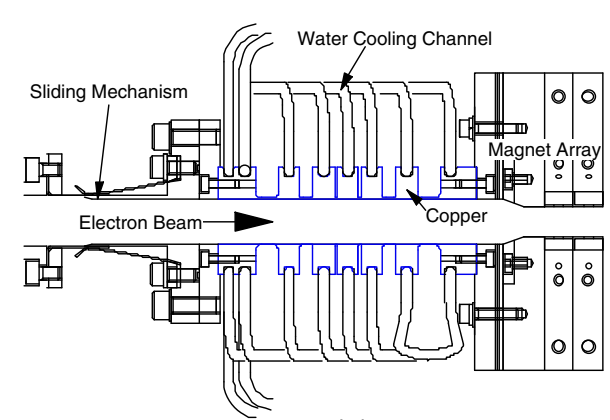

(a)

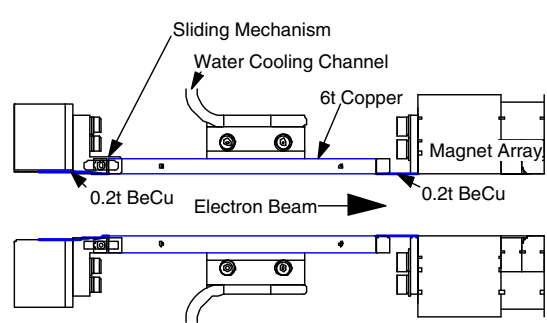

(b)

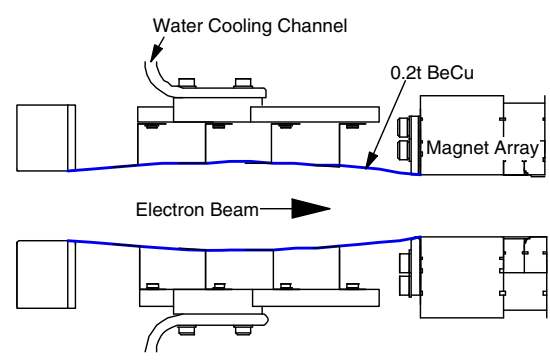

(c)

FIG. 2. Sketch of different designs for the transition taper: (a) cellular radiator type (similar to that used in SLS), (b) drawbridge type (TPS) and (c) thin $\mathrm{BeCu}$ type (similar to that used in SPring-8).

allowed temperature rise of 25 degrees is sufficient for operation at $3 \mathrm{GeV}$ and $500 \mathrm{~mA}$. At SPring-8, a $\mathrm{BeCu}$ woven strip [44] is designed to transform the geometry from an elliptical storage ring vacuum chamber to an undulator magnet array [a similar type is shown in Fig. 2(c)]. The use of thin $\mathrm{BeCu}$ strips, though, results in a low cooling capacity of only a few watts.

\section{CRYOGENIC PERMANENT MAGNET UNDULATOR}

IVUs, CPMUs and SCUs represent recent development trends for short period undulators, where the latter two can provide a higher magnetic field with a shorter undulator period length compared to an IVU. As described before, standard undulators serve for broad scientific applications. The deflection parameter, $K$, should be larger than 2 to generate higher harmonics with high intensity. Taking into account thermal insulation or impedance issues, gap losses cannot be avoided in a SCU and CPMU. The typical gap loss in a CPMU is currently $0.2 \mathrm{~mm}$, however, in a SCU, the loss is larger than $1 \mathrm{~mm}$ (ANKA SCU15) or $2.3 \mathrm{~mm}$ (APS SCU0). Figure 3 demonstrates the relation between the vacuum gap and the period length for $K=2$ in undulators of various types under the assumption that the gap loss is $1.0 \mathrm{~mm}$ for SCU, and $0.2 \mathrm{~mm}$ for CPMU and IVUs. The figure provides a guideline for the shortest period length that can be achieved for a given desired vacuum gap.

The SCU with $\mathrm{Nb}_{3} \mathrm{Sn}$ superconductor can provide the highest magnetic flux with the shortest undulator period length although technical challenges remain in its development (Fig. 3). A NbTi SCU can reach higher magnetic fields compared to a CPMU with the same vacuum gap if the period length is more than one $\mathrm{cm}$. On the other hand, a CPMUs can be designed for a smaller gap generating a higher magnetic field owing to its high resistance to beam induced heat load.

The in-vacuum girder of a CPMU is generally made of aluminum or copper to benefit from a high thermal conductance. With a large cooling capacity from cryocoolers or a liquid nitrogen $\left(\mathrm{LN}_{2}\right)$ thermosiphon, the allowed heat load can reach several hundred watts (includes beam-induced heat load, conduction and radiation heat transfer), which is confirmed by the existence of a commercially available cryocooler with a cooling capacity of $600 \mathrm{~W}$ at $80 \mathrm{~K}$ (AL600, CRYOMECH). In a SCU, the superconducting coil is impregnated with epoxy resin, so a beam chamber is necessary to separate the UHV beam vacuum from the isolation vacuum for the superconducting coils.

The development at KEK of a CPMU was originally motivated by a nonbaking strategy where the outgassing from PMs is suppressed at CT [40] and by the fact that the performance of rare-earths-based PMs greatly improve at low temperatures. The remanence and coercivity of PMs increases monotonically for lower temperatures except for $\mathrm{NdFeB}$, which reaches a maximum remanence at around $150 \mathrm{~K}$. The stable operation of CPMUs in storage rings encourages widespread application in SR facilities, as evidenced by many new projects in progress at DLS [46], HZB [47], TPS [48] and SOLEIL LUNEX5 [49]. Table II

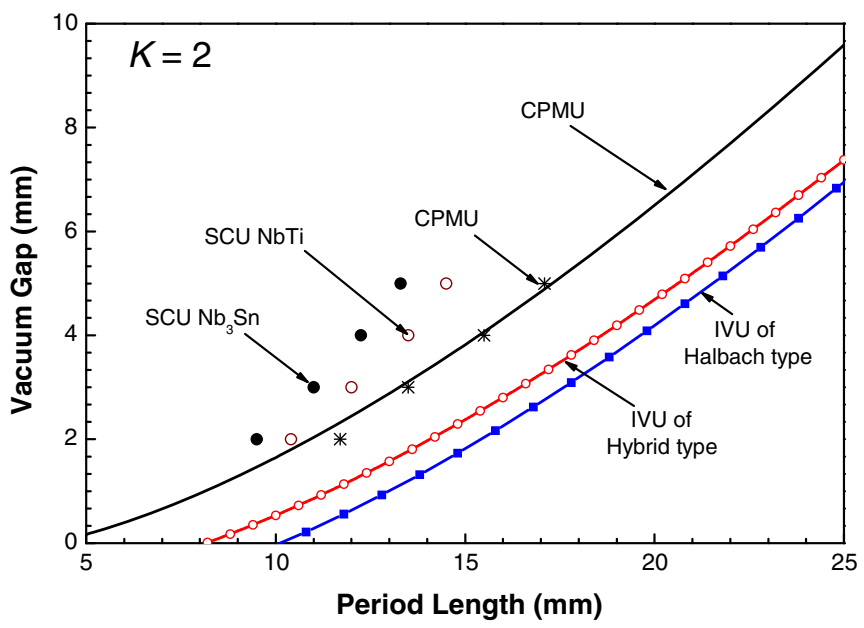

FIG. 3. Relation between vacuum gap and minimum period length for $K=2$. The symbol data for CPMUs and SCUs are taken from [45], while the material for the CPMUs and IVUs is $\mathrm{PrFeB}(\mathrm{Br}=1.67 \mathrm{~T})$ and $\mathrm{NdFeB}(B r=1.2 \mathrm{~T})$, respectively. The gap loss is assumed to be $1 \mathrm{~mm}$ for SCUs, and $0.2 \mathrm{~mm}$ for CPMU and IVUs. 
TABLE II. Development of CPMUs around the world.

\begin{tabular}{|c|c|c|c|c|c|c|c|c|c|c|c|}
\hline & $\begin{array}{l}\text { Period } \\
\text { length } \\
(\mathrm{mm})\end{array}$ & Status & $\begin{array}{c}\text { Magnet } \\
\text { type }\end{array}$ & $300 \mathrm{~K}$ & $\begin{array}{l}3 \mathrm{r}(\mathrm{T}) \\
150 \mathrm{~K} \\
(\mathrm{Nd}) / 77 \mathrm{~K} \\
(\mathrm{Pr}, \mathrm{PrNd})\end{array}$ & & $\begin{array}{c}(\mathrm{kA} / \mathrm{m}) \\
150 \mathrm{~K} \\
(\mathrm{Nd}) / 77 \mathrm{~K} \\
(\mathrm{Pr}, \operatorname{PrNd})\end{array}$ & Magnet & $L_{u}(\mathrm{~m})$ & $\begin{array}{l}\text { Magnetic/ } \\
\text { vacuum } \\
\text { gap }(\mathrm{mm})\end{array}$ & $\begin{array}{c}\text { Operating } \\
\text { temperature } \\
(\mathrm{K})\end{array}$ \\
\hline \multicolumn{12}{|c|}{ CPMUs for storage rings } \\
\hline ESRF No. 1 & 18 & Operating & $\mathrm{Nd}$ & 1.16 & 1.31 & 2600 & 4620 & NEOREM 595t & 2 & $6.0 / 5.8$ & 150 \\
\hline ESRF No. 2 & 18 & Operating & $\mathrm{Nd}$ & 1.37 & 1.50 & 1275 & 3600 & Vacodym 764 & 2 & $6.0 / 5.8$ & 150 \\
\hline DLS/Dyanfysik & 17.7 & Operating & $\mathrm{Nd}$ & 1.31 & 1.43 & 1670 & & Vacodymn 854TP & 2 & $4.0 /$ & 150 \\
\hline SOLEIL No. 1 & 18 & Operating & $\operatorname{Pr}$ & 1.35 & 1.58 & 1355 & 6090 & NEOMAX 53CR & 2 & $5.5 / 5.3$ & 77 \\
\hline SLS & 14 & Operating & $\mathrm{Nd}$ & 1.33 & 1.50 & 1670 & 3980 & NEOMAX 45SH & 2 & $3.8 / 3.6$ & 135 \\
\hline SPring-8 & 15 & Not in use & $\mathrm{Nd}$ & 1.36 & 1.48 & 1273 & 3025 & NEOMAX 49CH & 1.4 & $3.8 / 3.6$ & 140 \\
\hline SSRF & 20 & Operating & $\mathrm{Nd}$ & 1.32 & 1.53 & 1580 & 4000 & $\mathrm{~N} 48 \mathrm{H}$ & 1.6 & $6.0 / 5.8$ & 120 \\
\hline ESRF No. 3 & 14.4 & Operating & $\operatorname{Pr}_{0.8} \mathrm{Nd}_{0.2}$ & 1.40 & 1.63 & 1640 & 6000 & Vacodymn 131DTP & 2 & $5.0 / 4.8$ & 77 \\
\hline SOLEIL No. 2 & 18 & Construction & $\operatorname{Pr}$ & 1.35 & 1.58 & 1355 & 6090 & NEOMAX 53CR & 2 & $5.5 / 5.3$ & 77 \\
\hline DLS & 17.6 & Construction & $\operatorname{Pr}_{0.8} \mathrm{Nd}_{0.2}$ & 1.38 & 1.62 & 1640 & 5340 & VAC & 2 & $5.6 / 5.0$ & 77 \\
\hline TPS & 15 & Construction & $\operatorname{Pr}$ & 1.40 & 1.67 & 1680 & 6200 & NEOMAX 68CU & 2 & $4.0 / 3.8$ & 77 \\
\hline HZB/BESSY II & 17 & Construction & $\operatorname{Pr}_{0.8} \mathrm{Nd}_{0.2}$ & 1.38 & 1.58 & 1640 & 5340 & VAC & 1.6 & $5.3 / 5.0$ & 77 \\
\hline \multicolumn{12}{|c|}{ CPMUs for linac-based XFELs } \\
\hline $\begin{array}{l}\text { HZB/ } \\
\text { Universität }\end{array}$ & 15 & Construction & $\operatorname{Pr}_{0.8} \mathrm{Nd}_{0.2}$ & 1.38 & 1.58 & 1640 & 5340 & VAC & 2 & $2.3 / 2.0$ & $\ll 77$ \\
\hline $\begin{array}{l}\text { Hamburg } \\
\text { SOLEIL No. } 3\end{array}$ & 15 & Construction & $\operatorname{Pr}$ & 1.35 & 1.58 & 1355 & 6090 & NEOMAX 53CR & 3 & $3.0 / 2.8$ & 77 \\
\hline
\end{tabular}

shows the development of CPMUs around the world. A CPMU becomes a favorite for short period undulator developments because of its attractive characteristics: (1) 20\%-30\% higher field compared to an IVU with the same magnet circuit design, (2) high resistance against radiation damage, (3) easy extension from IVU design, (4) reduction of image current heating on a magnet cover by factor of 2-3 compared to an IVU and (5) a manageable heat budget up to several hundred watts, which is much higher than that in a SCU.

\section{A. Choice of magnet and cooling method}

Magnets built from $\mathrm{NdFeB}$ [22], PrFeB [25] and $\left(\mathrm{Pr}_{0.8} \mathrm{Nd}_{0.2}\right) \mathrm{FeB}$ [50] materials are commonly used in CPMUs. As is well known, the usage of a NdFeB PM is limited to $140-150 \mathrm{~K}$ because of a magnet spinorientation transition phenomenon, whereas, a PrFeB PM has no such limitation. The concept of a CPMU was proved after measuring the characteristic of $\mathrm{NdFeB}$ and PrFeB at SPring-8 [22], and both, remanence and coercivity, are found to increase at CT. The magnetic field of a CPMU based on $\mathrm{Pr}_{2} \mathrm{Fe}_{14} \mathrm{~B}$ (NMX-53CR) was measured in a prototype with a period length of $18 \mathrm{~mm}$ and four periods at SOLEIL. The result shows that the field gain is $13 \%$ while PMs are cooled down from room temperature (RT) to $80 \mathrm{~K}$ [25]. Another material, (PrNd)-Fe-B alloy, was developed for low temperature applications and an optimized composition of $\left(\mathrm{Pr}_{0.8} \mathrm{Nd}_{0.2}\right){ }_{2} \mathrm{Fe}_{14} \mathrm{~B}$ is proposed [50]. At $30 \mathrm{~K}$, the remanence and coercivity of $\left(\mathrm{Pr}_{0.8} \mathrm{Nd}_{0.2}\right)_{2} \mathrm{Fe}_{14} \mathrm{~B}$ reach $1.69 \mathrm{~T}$ and $5700 \mathrm{kA} / \mathrm{m}$, respectively, which shows that the field gain is $15 \%$ when cooled down to $80 \mathrm{~K}$ [27]. After the performance of a $\mathrm{PrFeB}$ and (PrNd)FeB CPMU has been proven, the use of these materials has become the preferred choice for the development of CPMUs. Adoption of a magnet material with higher remanence and moderate coercivity at RT hence becomes practical at $\mathrm{CT}$. In addition, differently from the IVU case, thermal treatments of PMs are unnecessary because a CPMU fabricated at RT is operated at CT. However, the coercivity at RT must exceed $1000 \mathrm{kA} / \mathrm{m}$ [51] to avoid demagnetization during magnet assembly at RT.

Figure 4 shows the temperature dependence of the magnetic fields for various PM materials that can be selected for a CPMU. A Lake Shore Cryotronics Hall probe (HGCT-3020), fixed on the magnet surface, is used to measure the magnetic field at different temperatures. The dimensions of all samples are $10 \mathrm{~mm}(\mathrm{~W}) \times 10 \mathrm{~mm}(\mathrm{~L}) \times$ $5 \mathrm{~mm}(\mathrm{H})$ with the same permeance close to unity. The distance between the sensor and the magnet surface is about

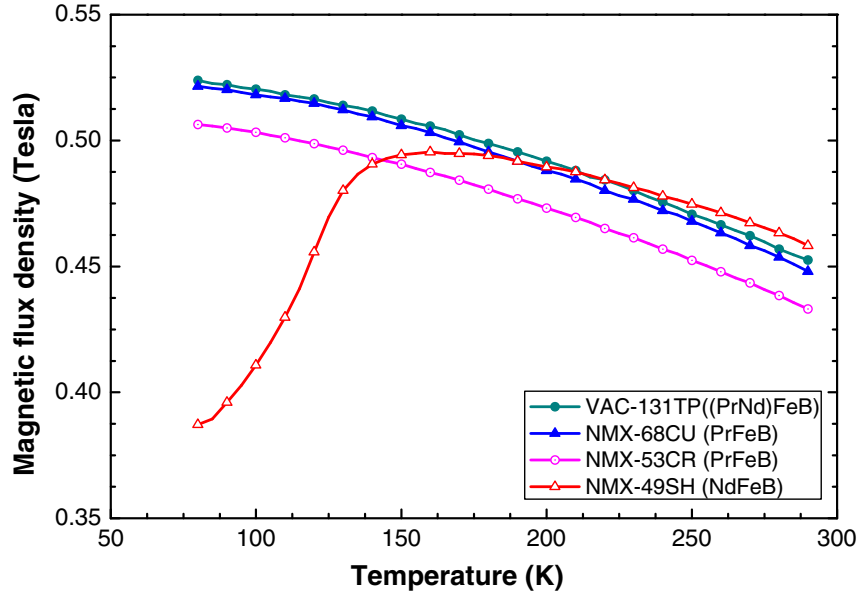

FIG. 4. Temperature dependence of the magnetic field density in various magnets [48]. The dimensions of all samples are $10 \mathrm{~mm}(\mathrm{~W}) \times 10 \mathrm{~mm}(\mathrm{~L}) \times 5 \mathrm{~mm}(\mathrm{H})$ (the magnetization direction) with the same permeance close to unity. 
$0.5 \mathrm{~mm}$ and is shown in Fig. 4. The $\mathrm{NdFeB}$ magnet (NMX-49SH) has a maximum magnetic field around $150 \mathrm{~K}$ and drops sharply at lower temperatures, while all PrFeB PM samples show a monotonic increasing of magnetic field at low temperatures. The magnetic field of $\mathrm{PrFeB}$ magnets (NMX-68CU and VAC-131TP) at LNT increases around $15 \%$ from that at $300 \mathrm{~K}$. If these PMs are used in a CPMU, the peak magnetic field may be proportional to the field of the samples and, therefore, the measured data shown in Fig. 4 may reflect the actual magnetic performance of a CPMU.

Both, liquid nitrogen $\left(\mathrm{LN}_{2}\right)$ cooling $[28-34,46]$ and a cryocooler [47,52,53], have been used for CPMUs. With cryocoolers, a higher magnetic performance for $(\mathrm{PrNd}) \mathrm{FeB}$ and PrFeB CPMUs can be obtained because the magnets can be cooled down below LNT. A cryocooler is thus an effective choice for a Pr-based CPMU as well as for a facility where a $\mathrm{LN}_{2}$ transfer line is not available. A closedloop $\mathrm{LN}_{2}$ system may be an economic option for multiple CPMU operation in the long run compared to cryocoolers requiring periodic maintenance. A thermosiphon cooling system with $\mathrm{LN}_{2}$ [46] can provide a high cooling capacity and can be efficient for several CPMUs operated concurrently. However, the drawback of the $\mathrm{LN}_{2}$ cooling method is the lack of flexibility to decrease the PMs temperature below LNT.

\section{B. Deformation and temperature variation on magnet arrays}

In CPMUs operating at CT, the thermal material characteristics are an important issue. Material contraction at low temperatures causes the gap to widen by several hundred micrometers relative to RT, arising mainly from the thermal in-vacuum girder contraction. During construction, a moving wire method [54] can be used to determine the vacuum gap at low temperatures. A feed-forward table to record the difference between the gap encoder readings and the vacuum gap shall be implemented for the operation of CPMUs in accelerators. An alternative method is to use an optical micrometer for vacuum gap monitoring [24] which can be applied during CPMU operation in a storage ring. However, there is the potential risk of radiation damage of the electronic devices, so the preparation of a feed forward table is recommended for routine operation.

In a CPMU with a short period length, the magnetic force can be very high due to the enhanced magnetic field capability. For example, for the TPS-CPMU with a period length of $15 \mathrm{~mm}$ at the gap of 3 or $4 \mathrm{~mm}$, the magnetic force per unit length reaches 28.5 or $16 \mathrm{kN} / \mathrm{m}$, respectively. As presented in a subsequent section, a counterforce system could be an effective solution for magnetic force compensation to construct a compact mechanical frame.

The magnet temperature is the result between cooling power and several heat loads derived from (1) the thermal conduction via the bellows-link rods or the transition taper,
(2) the thermal radiation from the vacuum chamber surface and (3) the beam-induced heat load. The number of bellows-link rods must be a compromise between maintaining a low phase error caused by the deformation of the in-vacuum girders and low conduction heat transfer from the bellows-link rods. As most of the heat load comes from the bellows-link rods, a special design of hollowed link rods filled with insulation materials can reduce the conduction heat transfer by a factor of 5-10. A stable temperature of the PMs is important to obtain a reproducible energy spectrum for different beam conditions, and therefore localized heaters attached to the in-vacuum girders can be used to compensate for the variation of beam-induced heat load [52] from different beam currents, undulator gaps and bunch-filling patterns. The linear power density generated by the heaters shall be uniform along the in-vacuum girder to avoid a local gap error, which can cause an increase of the phase errors.

A phase error at CT may be increased from that at RT due to temperature variations along magnet arrays, as will be explained in more detail in Sec. IV B. From practical experience at ESRF [29] and SOLEIL [55], the temperature variation along an aluminum-alloy girder with $\mathrm{LN}_{2}$ cooling is about $1-2 \mathrm{~K} / \mathrm{m}$. To obtain a smaller thermal variation along the magnet arrays (target $<0.1 \mathrm{~K} / \mathrm{m}$ ), future CPMU designs should be based on (1) OFHC girders with higher thermal conductivity compared to aluminum, (2) several heaters with precise temperature controls or (3) optimized cooling points for cryocoolers.

\section{In situ magnetic measurement system}

One of the main tasks in the development of a CPMU is to characterize the magnetic field at CT and to correct gap errors due to temperature variations. To measure the magnetic field of a CPMU at CT, a compact in situ Hallprobe measurement system shall be installed within the vacuum. In general, the Hall probes used for such field measurements should be calibrated properly and its positioning errors should be minimized to preserve low undulator phase errors. In addition, the probe shall be slim to fit into a tight undulator gap of 3-4 mm. As the Hall sensor is cooled by nearby cold magnets, a temperaturedependent calibration of the Hall probe is necessary and all components of the system must be UHV compatible to avoid contamination. At SPring-8, TPS $[24,56]$ and SLS in situ measurement systems based on laser-positioned components with a feedback system are used. The Hallprobe carrier is moved along a customized rail located in the vacuum chamber where the magnet arrays of the undulator are arranged, and the longitudinal position of the Hall probe is determined by a laser interferometer. The transverse position of the Hall probe can be determined by two sets of laser beams and position sensitive detectors (PSD). One of the laser beams injected from one side of the undulator irradiates one of the two irises mounted 
on the Hall-probe carrier and an image of the iris is created on one of the PSDs located at the other side of the undulator. In the same way, the image of the other iris is created on the other PSD. Thus, the transverse position of the Hall probe is determined. Since the rail is movable in the transverse direction by motorized stages, the positional offset of the Hall probe from the proper position can be corrected automatically. Except for the laser system, the measurement system is enclosed in the vacuum chamber.

For the measurement system at ESRF and SOLEIL [31,54], a vacuum chamber with a subsidiary chamber was designed. The subsidiary chamber is necessary for a linear guide rail and the Hall-probe carrier while the undulator magnet arrays are located in the main chamber. The motorization device is located in air and drives the Hall-probe carrier through magnetic coupling. The longitudinal position of the probe is measured by a Michelson interferometer or a laser tracker. A Hall probe moves along the linear guide rail and the vertical position errors of the probe caused by rail tolerances are measured with an optical system. The magnetic field measured is then corrected taking into account the rail tolerances.

The in situ measurement system in HZB consists of five piezoactuators and five optical measurement devices [57]. The Hall-probe carrier is moved by stainless steel strings. The two lasers are placed in air and laser beams pass through pinholes on the carrier, and illuminate the PSDs in vacuum. Thus, the transverse position and roll angle error about the longitudinal axis can be obtained. A three-axis Michelson interferometer with a mirror on the carrier can determine the longitudinal position and the yaw and pitch angles of the Hall probe. All degrees of freedom in the Hallprobe positioning (orientation and displacement) can be corrected by piezoactuators in combination with a feedback system.

\section{IMPORTANT ISSUES IN AN IVU AND CPMU}

Since the technologies of IVUs are mature at present, technological challenges in IVUs and CPMUs are focused on the development of shorter period undulator with a small gap. The minimum vacuum gap of an IVU in a storage ring is limited by the beam lifetime, the dynamic aperture for injection, the betatron functions, radiation damage of magnet materials, the beam-induced heat load and an operational safety margin. For a short period undulator, a hybrid undulator is more suitable than a pure Halbach type, since the former, with ferromagnetic materials, provides some gain in magnetic flux intensity. Besides, problems specific to small gap IVUs and CPMUs, like phase errors derived from the deformation of the in-vacuum or out-of-vacuum girders, the beam-induced heat load and radiation-induced demagnetization are important considerations for the design.

\section{A. Phase error issue}

A low phase error of an IVU is essential to reach high undulator radiation brightness, especially at higher harmonics. Phase errors in an IVU can result from (1) deformation of in-vacuum and out-of-vacuum girders at a small gap, (2) thermal effects on the magnet arrays and (3) poor reproducibility of the IVU gap after reassembly. When IVU/CPMUs operate at a small gap, a large girder deformation along the undulator axis may lead to gap errors due to magnetic forces. Such gap errors can result in increased phase errors even for ideal magnet array assemblies. We call this kind of systematic phase error an "intrinsic phase error." Since the net rms phase errors of the undulator are derived not only from errors in the magnet arrays but also gap errors arising from deformations, intrinsic phase errors are a serious issue for short period and small gap undulators. The undulator magnetic field can be determined by the empirical formula,

$$
B=B_{0} \exp \left[b_{1}\left(\frac{g}{\lambda_{u}}\right)+b_{2}\left(\frac{g}{\lambda_{u}}\right)^{2}\right]
$$

where $g$ is the magnetic gap and $B_{0}, b_{1}$ and $b_{2}$ are fitting coefficients. In general, all of these coefficients have finite values in hybrid undulators, while in a Halbach type, $b_{1}=-\pi$ and $b_{2}=0$. For example, the coefficients for the TPS-CU15 (CPMU) at RT are $B_{0}=4.061, b_{1}=-5.251$ and $b_{2}=2.079$. When the undulator is cooled only the coefficient $B_{0}$ increases to 4.625 at LNT, while the other parameters stay constant. A relative field error can be obtained from Eq. (1) as

$$
\frac{\Delta B}{B}=\left(b_{1}+2 b_{2} \frac{g}{\lambda_{u}}\right) \frac{\Delta g}{\lambda_{u}},
$$

where $\Delta g$ is the gap error. As shown in Fig. 5, the relative field error, $|\Delta B / B|$, derived from the gap error increases with smaller gap and shorter period lengths.

In Fig. 5 the slope of the lines can be considered as an $f$ value, defined by the ratio of the relative field error to the relative gap error, given by

$$
f=-\frac{\Delta B}{B} \frac{\lambda_{u}}{\Delta g}=-b_{1}-2 b_{2} \frac{g}{\lambda_{u}} .
$$

The $f$ value gives the gap-error-induced field error which depends on the magnet design, the period length and the magnetic gap of an undulator. Figure 6 demonstrates an increasing $f$ value for small gaps in a CPMU of hybrid type while in the case of the Halbach type $\left(b_{2}=0\right)$ the $f$ value is independent of the gap.

The intrinsic rms phase error, based on Walker's investigation [11], is given by 


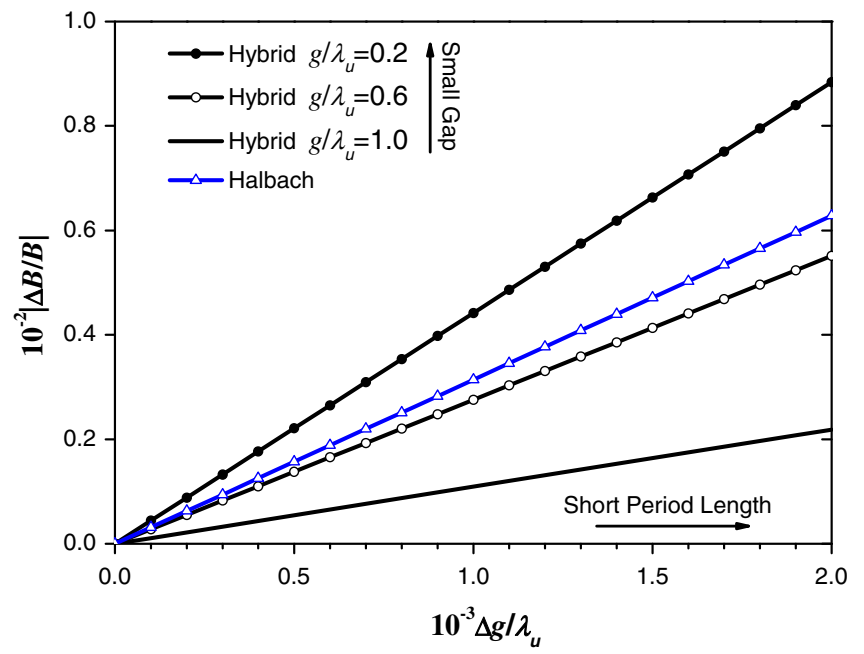

FIG. 5. Dependence of the relative field error on gap errors in the CPMU (TPS-CU15). For comparison, the dependence in a Halbach type is also shown.

$$
\sigma_{\mathrm{INT}}=k_{b} \pi \frac{K^{2}}{1+K^{2} / 2} \frac{L}{\lambda_{u}}\left|\frac{\Delta B}{B}\right|_{\max },
$$

where $L$ denotes the undulator length or the interval of the bellows-link rods shown in Fig. 1 , and $k_{b}$ is the coefficient depending on the shape of the deformation. Substituting Eq. (3) into Eq. (4), the intrinsic rms phase error can be written as

$$
\sigma_{\mathrm{INT}}=k_{b} \pi \frac{K^{2}}{1+K^{2} / 2} \frac{L}{\lambda_{u}}\left|f \frac{\Delta g_{\max }}{\lambda_{u}}\right|
$$

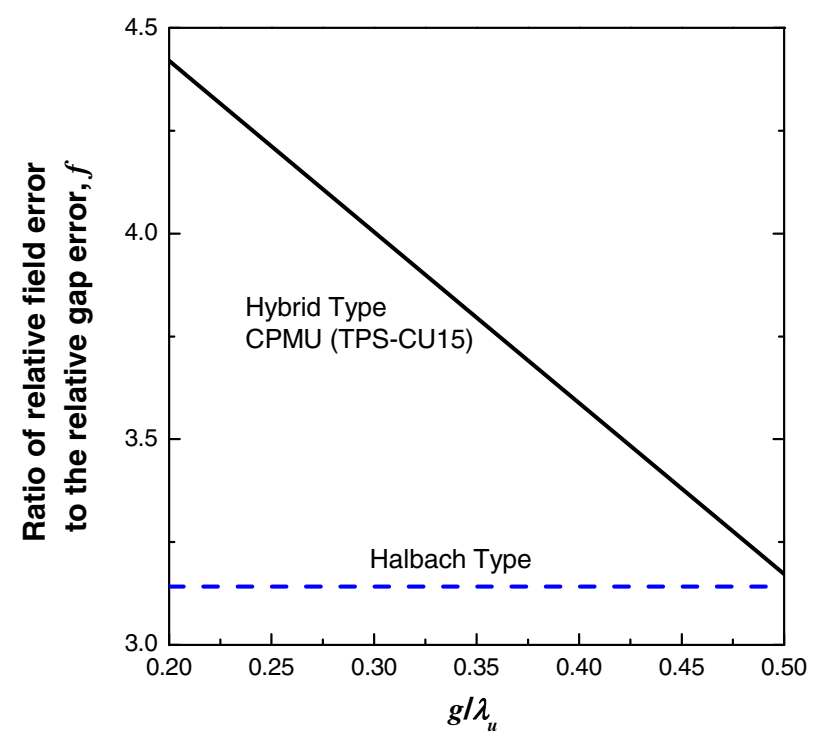

FIG. 6. Dependence of the $f$ value, the ratio of relative field error to the relative gap error, on the relative magnetic gap, $g / \lambda_{u}$, in a CPMU (TPS-CU15).
This equation shows that the intrinsic rms phase error increases with the $K$ value, shorter period length, larger undulator length and a larger gap error. If the deformation, $\Delta g / 2$, of the girder along the longitudinal axis is known, the intrinsic rms phase error can be obtained directly from which the $k_{b}$ values are obtained for various types of deformation.

As the model undulator to investigate the intrinsic phase error issue we use again the CPMU (TPS-CU15) for which Table I shows all relevant parameters resulting in an $f=$ 4.41 as shown in Fig. 6. Other parameters, second moment of area and Young's modulus, for the evaluation of the deformation are also compiled in Table I. Figure 7 shows the deformation derived from different kinds of support configurations: A, two pinned joints at both ends; B, two pinned joints at optimum points for minimum deviation; $\mathrm{C}$, four pinned joints at optimum points for minimum deviation; and $\mathrm{D}$, many pinned joints at regular intervals. The configurations A, B and C correspond to the out-ofvacuum girder ( $L=L_{u}$, undulator length) and D to the invacuum girder ( $L=L_{\text {rod }}$, interval between two rods). The optimum conditions for smallest gap errors in the configurations $\mathrm{B}$ and $\mathrm{C}$ are shown in the figure.

As shown in Table III and Fig. 8, the intrinsic rms phase errors for different support configurations are obtained from a numerical code under the assumption of a uniformly distributed magnetic force. Configuration B is adopted all over the world, but adoption for the CU15 results in $\sigma_{\text {INT }}$ to be 1.9 degrees, which is too large to obtain a net value for the rms phase error of less than 2.0 degrees. For the CU15, therefore, configuration $\mathrm{C}$ is adopted with a very low intrinsic rms phase error of 0.043 degree. For an in-vacuum girder, the intrinsic phase errors can be further reduced by increasing the number of bellows-link rods. Equation (5) and $k_{b}$ values from Table III can be used to determine the intrinsic rms phase error for the four configurations discussed above, but for other support configurations

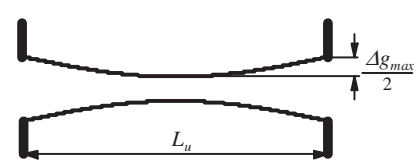

(a)

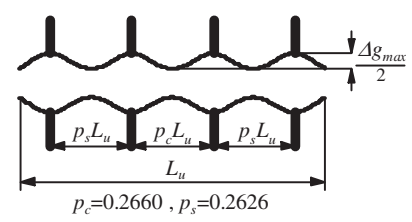

(c)

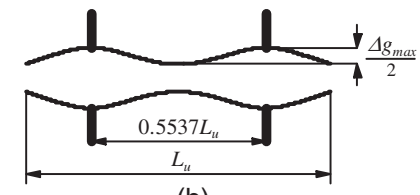

(b)

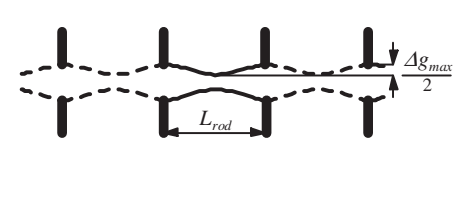

(d)
FIG. 7. Various support configurations for out-of-vacuum/ in-vacuum girders: (a) two pinned joints at both ends, (b) two pinned joints at optimum points for minimum deviation, (c) four pinned joints at optimum points for minimum deviation, and (d) many pinned joints at regular intervals. 
TABLE III. Intrinsic rms phase errors, $\sigma_{\mathrm{INT}}$, for various support configurations. As a model undulator, the TPS-CU15 (CPMU) is assumed (Table I). The magnetic force is assumed as $57.2 \mathrm{kN}$ for the configurations $\mathrm{A}, \mathrm{B}$ and $\mathrm{C}$, and $7.3 \mathrm{kN}$ for the configurations $\mathrm{D}$ (interval of bellows-link rod, $L_{\mathrm{rod}}=0.255 \mathrm{~m}$ ).

\begin{tabular}{lccc}
\hline \hline Support configuration & $\left|\Delta g_{\max }\right|(\mu \mathrm{m})$ & $\sigma_{\text {INT }}($ degree $)$ & $k_{b}$ \\
\hline A & 137 & 74 & 0.052 \\
B & 2.9 & 1.9 & 0.063 \\
C & 0.14 & 0.043 & 0.030 \\
D & 2.3 & 0.18 & 0.066 \\
\hline \hline
\end{tabular}

numerical calculation is still necessary. In a storage ring SR facility, a tapered undulator may be used to obtain a wide spectral width of radiation, which actually means an intentional increase of the phase errors at the expense of brilliance. In most cases, however, such an undesirable taper from a defect in the undulator mechanism must be avoided. The intrinsic rms phase error for tapered undulators can also be obtained from Eq. (4) or (5) where the value $k_{b}$ is estimated numerically as 0.074 .

Since the magnetic force increases exponentially with decreasing undulator gap, a narrow magnet pole width or a counter force system might be employed to keep the girder deformation to a minimum or to make a compact gapdriven system. In present storage rings, however, a narrow magnet/pole may result in an increased transverse magnetic field roll-off causing an increase of dynamic field integrals [58] along the particle path especially during injection. A high dynamic field integral can also result in a reduced dynamic aperture. In a future storage ring, however, injection methods may be used that eliminate or minimize transverse betatron oscillations, thus reducing the required good field region and the magnet poles can be made narrower. Even though, the adoption of a counter force system is still necessary for an IVU with a small gap to

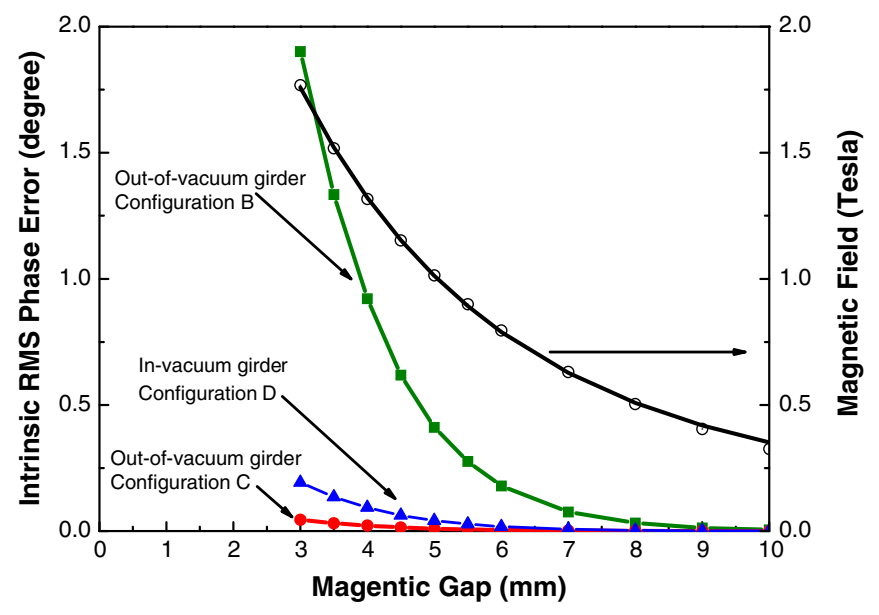

FIG. 8. Dependence of the intrinsic rms phase error and magnetic field as a function of the magnetic gap in the TPS CPMU for various support configurations. compensate the magnetic force and obtain low intrinsic rms phase errors. Such systems, of course, should have no effect on the magnetic field along the undulator axis and should be protected from SR emitted by the upstream bending magnet. In addition, a simple structure should be adopted inside the vacuum to avoid the risk of vacuum system failure in a storage ring and to obtain sufficient access for the field measurement system. Force-compensation systems of three types have been proposed for insertion devices. (1) For a repulsive force generated by additional PMs, two-sided magnet arrays with opposite magnetization from the main magnet array are applied to a revolver undulator in SPring-8 [59]. Following this concept, a costeffective multipole monolithic PM has been tested for a small gap IVU [60]. (2) A spring system is applied for an in-vacuum wiggler at SOLEIL [61]. Nonmagnetic spring coils with two spring coefficients are installed at both sides of the magnet arrays for force compensation. (3) A conical spring system with exponential characteristics for an APS vertical polarization undulator can allow a close fit to the magnetic forces for compensation [62]. Meanwhile, for the CPMU (TPS-CU15) based on a four-support configuration (configuration $\mathrm{C}$ in Fig. 7), spring compensation modules of a compact type will be introduced at each of the four support points. This module was developed recently by NEOMAX ENGINEERING Co., Ltd.

Degradation of phase errors derived from thermal effects may occur during storage ring operation in case of a high beam-induced heat load with insufficient cooling power. For $\mathrm{NdFeB}$ magnet blocks, the temperature coefficient of the remanence is at RT generally $-0.06 \% / \mathrm{K}$ as shown in Fig. 4 or $-0.6 \%$ for a temperature increase of $10 \mathrm{~K}$. The linear power density of SR emitted by an upstream bending magnet varies along the longitudinal beam path. The uneven thermal distribution can cause increased phase errors during operation of the storage ring.

When a CPMU is cooled from RT to CT, such an uneven temperature distribution can lead to (1) gap errors from thermal contraction of materials (magnet keepers, in-vacuum girders and bellows-link rods) and (2) variations of remanence along the PM magnet arrays. Mixture of thermal material contraction and changes of magnet properties can cause field and phase errors. For example, in the CPMU (TPS-CU15) magnet arrays, the temperature decreases monotonic from the entrance to the exit of the undulator and the CPMU works like a "tapered undulator" with increasing phase errors determined by Eq. (4) with $k_{b}=0.074$. The relative field error due to thermal effects is given by

$$
\frac{\Delta B}{B}=-f \frac{\Delta g_{\max }}{\lambda_{u}}+\frac{\Delta B r}{B r}
$$

where the first term is derived from the thermal expansion, and the second from the temperature dependence of the PM remanence. 
In case of the CU15, the height of the in-vacuum OFHC girder including the magnet keeper is about $90 \mathrm{~mm}$ and the length of the stainless-steel bellows-link rod is about 100 $\mathrm{mm}$. One end of the bellows-link rod is fixed on the out-ofvacuum girder at RT, and the other end on the in-vacuum girder at LNT. The linear thermal expansion coefficient is expected to be about $1 \times 10^{-5} / \mathrm{K}$ at LNT. Assuming that the temperature difference between the undulator entrance and exit is $1 \mathrm{~K}$, the expansion of the in-vacuum girder and bellows-link rod at the exit can be roughly estimated to be 0.9 and $0.5 \mu \mathrm{m}$, respectively, and, as a result, the corresponding gap difference is $\Delta g_{\max }=-2.8 \mu \mathrm{m}$. When the CU15 is operating at a magnetic gap of $3 \mathrm{~mm}$ with $K=2.48$, the $f$ value is 4.41 as shown in Fig. 6 and the first term of Eq. (6) is estimated to be equal to $8.2 \times 10^{-4}$. Since the temperature coefficient for the remanence of $\mathrm{PrFeB}$ is estimated to be $-1 \times 10^{-4} / \mathrm{K}$ at LNT (Fig. 4), the second term of Eq. (6) becomes equal to $-1 \times 10^{-4}$ giving a net relative field error of $7.2 \times 10^{-4}$. This in turn gives an intrinsic rms phase error of 2.0 degrees from Eq. (4), which is too large for a standard undulator with an overall rms phase error specification of less than 2 degrees. Therefore, the temperature variation along the undulator axis shall not exceed $1 \mathrm{~K}(0.5 \mathrm{~K} / \mathrm{m})$. The temperature gradient along the magnet arrays must be controlled to minimize field errors. In the CU15, such a deformation can be corrected by heaters mounted on the invacuum girders in combination with differential adjusters with submicrometer resolution [63] as shown in Fig. 1. An alternative method is to adopt a mechanical frame with a tapering function to compensate a residual linear temperature gradient.

Usually, field correction and measurement of an IVU is performed without vacuum chambers for easy access to the magnet array. After the magnet arrays are assembled in the vacuum chambers, the reproducibility of IVU gaps should be carefully controlled within a few micrometers. The required gap reproducibility is harder to reach for shorter undulator period lengths as shown in Fig. 5, where the field errors increase rapidly with decreasing period length. An in situ field measurement system is therefore desirable to verify accurately the in-vacuum undulator magnetic performance.

\section{B. Beam-induced heat load issue}

The beam-induced heat load (due to SR and image current heating) can impact a stable operation of an IVU/ CPMU at small gaps and degrade the performance of the undulator. In an early example, a stainless-steel (type 304) magnet cover melted from the combined effect of image current heating and SR irradiation [64], an effect we call "avalanche meltdown" [65]. The first sign for such a meltdown is thought to be image current heating of the stainless-steel cover, because of its high electric resistance. In addition, the thermal contact between the magnet surface and the stainless-steel cover is low because of the weak magnetic forces between them and, as a result, the thermal expansion of the cover caused its detachment from the magnet surfaces. The detached cover buckles and is irradiated by SR coming from the upstream bending magnet leading to melting. To lower the threshold level of this meltdown, copper foils coated with nickel have been used to not only obtain high electric conductivity but also a strong contact between the cover and the magnet surface. $\mathrm{SR}$ is responsible for an avalanche meltdown of the magnet cover while the image current mainly decreases the threshold of the power to cause an avalanche meltdown. The threshold for the power density to cause an avalanche meltdown is difficult to estimate, because it is affected by the flatness of the foil and the linear power density absorbed on a magnet cover is therefore recommended to be less than $10 \mathrm{~W} / \mathrm{m}$. It should be noted that this value is not a limit, but a rough indication for the maximum value from operational experience at SPring-8. A true limit of the power density on a magnet cover should be tested in various storage rings.

An undulator in a storage ring can be irradiated by SR coming from the upstream bending magnet. The vertical distribution of the angular power density of SR is given by [66]

$$
\begin{aligned}
\frac{d^{2} P_{B}}{d \theta_{x} d \theta_{y}} & =\frac{7 e \gamma^{5} I_{b}}{64 \pi \varepsilon_{0} \rho_{B}} f_{B}\left(\gamma \theta_{y}\right) \\
& =0.01808 \frac{I_{b} E_{\mathrm{GeV}}^{5}}{\rho_{B}} f_{B}\left(\gamma \theta_{y}\right)\left(\mathrm{kW} / \mathrm{mrad}^{2}\right),
\end{aligned}
$$

where

$$
f_{B}(x)=\frac{1}{\left(1+x^{2}\right)^{5 / 2}}+\frac{5 x^{2}}{7\left(1+x^{2}\right)^{7 / 2}} .
$$

In the above equations, $e$ is the electron charge, $E_{\mathrm{GeV}}$ the beam energy $(\mathrm{GeV}), \gamma$ the Lorentz factor, $I_{b}$ the beam current, $\varepsilon_{0}$ the permittivity of vacuum, $\rho_{B}$ the bending radius and $\theta_{y}$ the vertical angle. Figure 9 shows an example of the beam-induced heat load in the TPS CPMU (TPSCU15) under the assumption that the SR is passing along the undulator axis. The lines (a) and (b) indicate the CPMU at its smallest gap and at the gap during commissioning, respectively. The SR heat load on the undulator entrance increases with short vacuum gaps and reaches $400 \mathrm{~W}$ at zero vacuum gap $\left(g_{\text {vac }}=0\right)$. In case of CPMUs operating around LNT, such a high heat load is tolerable because high-capacity cryocoolers are available with high thermal conductance of the in-vacuum girder. On the other hand, the SR heat load on the magnet cover has a maximum of $50 \mathrm{~W}$ at a vacuum gap of $1.5 \mathrm{~mm}$. Although this power is not as high as in the undulator entrance case, it can cause an avalanche meltdown of the magnet cover in CPMUs. 


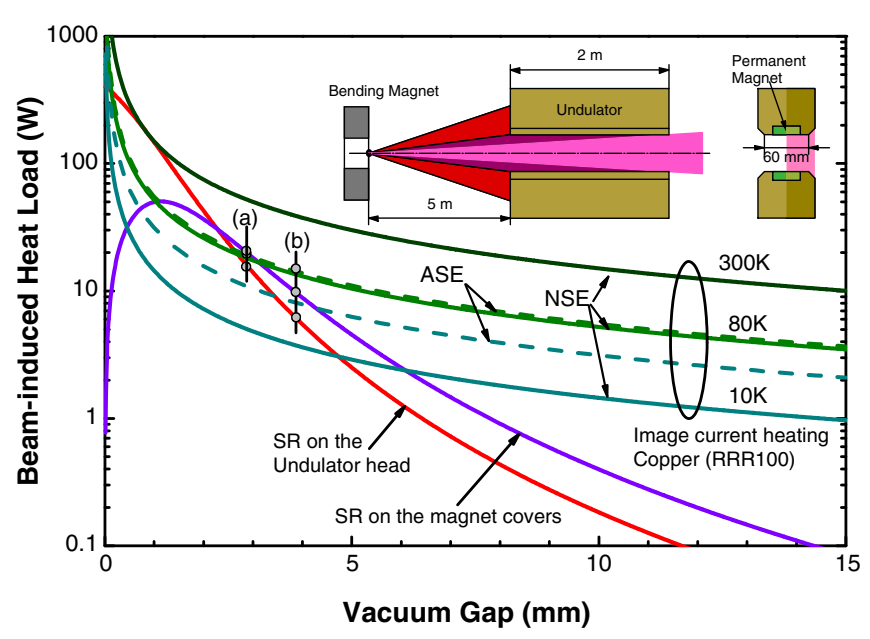

FIG. 9. Dependence of the beam-induced heat load on the vacuum gap in an IVU/CPMU. The red/purple curves denote the heat load due to SR on the undulator head/magnet covers, respectively. Heat load derived from indirect SR is not considered. The solid/dashed green curves denote the heat load due to image current heating under the assumption of normal/anomalous skin effect, respectively. The lines (a) and (b) indicate the CPMU (TPS-CU15) at its smallest gap and the gap during commissioning stage, respectively. The calculation is based on TPS parameters, $E_{\mathrm{GeV}}=3 \mathrm{GeV}, I_{b}=500 \mathrm{~mA}$, number of bunches $=600$, bunch length $=4.65 \mathrm{~mm}(15.5 \mathrm{psec})$, circumference $=518 \mathrm{~m}$, bending radius $=8.353 \mathrm{~m}$ and a distance of $5 \mathrm{~m}$ from the dipole magnet end to the undulator entrance.

The issue of indirect SR derived from simple reflection, fluorescence or Compton scattering can also be important for CPMUs and SCUs although the quantitative evaluation for such a heat load is difficult to estimate.

When the magnet temperature is around RT, the resistive wall heating due to image currents can be estimated under the assumption of a normal skin effect (NSE). The linear power density of resistive wall heating is uniformly distributed in the longitudinal direction and given by [67],

$$
\frac{d P}{d z}=\sum_{j=1}^{M} I_{j}^{2} \frac{\Gamma(3 / 4)}{\pi g \omega_{o} \sigma_{t}^{3 / 2}} \sqrt{\frac{\rho \mu_{o}}{2}},
$$

where the Gamma function $\Gamma(3 / 4)=1.2254, M$ is the number of bunches, $\sigma_{t}$ is the rms bunch length, $I_{j}$ is the bunch current, $\omega_{0}$ is the angular frequency of revolution, $\mu_{0}$ is the magnetic permeability of vacuum, and $\rho$ is the resistivity of the magnet cover. When the magnet temperature is very low, one shall include anomalous skin effect (ASE) [68]. As shown in Fig. 9, the heat load including ASE increases by about a factor of 2 at $10 \mathrm{~K}$, but by only $5 \%$ at $80 \mathrm{~K}$. In case of CPMUs operating around $80 \mathrm{~K}$, therefore, Eq. (8) is still effective because ASE can be ignored.

As shown in Eq. (8), the linear power density of the image current heating on the metallic surfaces depends on the bunch length, the filling pattern of the beam injection, the resistivity of the magnet cover and the undulator gap. Single bunch mode operation is an important option for user operations in a storage ring. In such an operation, the power density of the image current heat load could increase by a factor of 2 or 3 compared to that of uniform filling [64]. In general, a long bunch length, a low bunch current and low electrical resistance of the metallic surface is favorable for small gap IVU/CPMUs. The electrical resistivity of copper is reduced at lower temperatures, which is favorable for a CPMU because the magnet cover is cooled down to around LNT. In Fig. 9, the gap dependence of the heat load due to image current heating is also shown for a magnet cover made from OFHC (RRR100) at temperatures of 300,80 and $10 \mathrm{~K}$. Obviously, the heat load is lower at lower temperature. The image current heating on the magnet cover can be decreased at $80 \mathrm{~K}$ to one-third and at $10 \mathrm{~K}$ by one order of magnitude compared to that at RT (Fig. 9), where the reduced ratio depends on the residualresistivity ratio (RRR) of the OFHC magnet cover.

Several avalanche meltdowns of magnet covers in IVUs have been reported $[69,70]$ and are thought to be derived mainly from missteering of the beam orbit in the upstream bending magnet. Therefore, the electron orbit in the bending magnet must be aligned with the center of the IVU with a tight orbit interlock setting to prevent missteering. As an example of an orbit interlock, two beamposition monitors (BPMs) are recommended to measure also the direction of the SR. One BPM is located at the entrance of the bending magnet, the other at the exit. The interlock setting should depend on the undulator gap and beam conditions with a tighter threshold at small gaps. On rare occasions, such as for double collinear or canted undulators in a straight section, SR from the upstream undulator may irradiate the magnet cover of the downstream undulator causing severe damage. In this case, BPMs for the interlock should be located at the entrance/ exit of the upstream undulator.

Flatness of the magnet cover is also important, because SR irradiation of a local bump in the cover can cause a significant risk for avalanche meltdown. Such a local bump can be generated by manufacturing tolerances. Since manufacturing tolerances for magnets or keepers are 10 micrometers or more, they may create height differences from adjacent magnets. Given the same tolerances, the bump angles increase for shorter period lengths. As a result, the local power density on the bump of a magnet cover may be several times larger than that of a flat cover, thus increasing the risk for an avalanche meltdown. The heat load in the CU15 can be estimated from Fig. 9 to be $6.5 \mathrm{~W} / 17.2 \mathrm{~W}$ (SR on the undulator), $10.2 \mathrm{~W} / 21.2 \mathrm{~W}$ (SR on the magnet cover), and $13.7 \mathrm{~W} / 18.6 \mathrm{~W}$ (image current heating) for a vacuum gap of $3.8 \mathrm{~mm} / 2.8 \mathrm{~mm}$, respectively. The total cooling capacity of $400 \mathrm{~W}$ at $80 \mathrm{~K}$ is sufficient, but operation at a vacuum gap of $2.8 \mathrm{~mm}$ is 
thought to be challenging at best because the heat load and possible avalanche meltdown inside the gap is very high.

\section{Radiation damage}

The radiation-induced demagnetization of PMs is one of the major concerns in small gap undulators causing increased dynamic field integrals and phase errors [71-73] while a decrease in dynamic aperture with reduced undulator brilliance can be expected. So far, several incidents due to demagnetization of $\mathrm{NdFeB} \mathrm{PMs} \mathrm{in} \mathrm{out-}$ of-vacuum undulators have been reported [71-73]. On the other hand, none of the 29 IVUs operating with a minimum gap of $8 \mathrm{~mm}$ at the SPring-8 ring show signs of spectral degradation due to the demagnetization, which was confirmed by field measurement made on one IVU with PMs (NMX-35EH) after 11-year operation [74]. In general, $\mathrm{NdFeB} \mathrm{PMs} \mathrm{are} \mathrm{more} \mathrm{susceptible} \mathrm{to} \mathrm{radiation} \mathrm{damage}$ compared to SmCo PMs even with the same coercivity. For IVUs involving high temperature bakeout around $120^{\circ} \mathrm{C}$, therefore, special $\mathrm{NdFeB}$ PMs with sufficient coercivity and an appropriate thermal treatment (aging process) are absolutely necessary. Matter of course, such a consideration is unnecessary for out-of-vacuum undulators. Therefore, one may speculate that the difference in damage between IVUs and out-of-vacuum undulators may be caused by the countermeasures mentioned above. This speculation was found to be true by a radiation damage experiment at the $2 \mathrm{GeV}$ linac for the Pohang Light Source [37]. The experiment shows that if a $\mathrm{NdFeB}$ has sufficient coercivity $(\sim 2800 \mathrm{kA} / \mathrm{m})$ with thermal treatment, the radiation resistance can be increased to become comparable to SmCo PMs. However, the above treatment was found to be noneffective for IVUs installed in the linac-based XFEL facilitiy, SACLA. Some of the PMs in the IVU generated a reverse field [15]. It should be noted that the radiation damage in IVUs installed in a linac-based-XFEL is more noticeable, compared to IVUs in a storage ring, because the electron halo contains many more particles than the outer tails in a Gaussian distribution while the loss of electrons cannot be detected easily. In the case of storage rings, however, the loss is detected by highly precise lifetime measurements. For IVUs in linac based XFELs, a welldesigned collimator system to protect the undulators from being hit by electrons is required [14].

The risk of the radiation damage can be lowered by adopting $\mathrm{NdFeB} / \mathrm{PrFeB}$ magnets with high coercivity. From this point of view, the CPMU concept has a great advantage with respect to radiation damage issues. It has been reported that the coercivity of $\mathrm{NdFeB} / \mathrm{PrFeB}$ magnets can be enhanced at LNT by at least a factor of 4 [22]. Therefore, the radiation damage in CPMUs is thought to be not serious, which was confirmed for $\mathrm{NdFeB} / \mathrm{PrFeB}$ magnets in the electron irradiation experiment at low temperatures [75]. Nevertheless, it is prudent to minimize the risk of radiation damage. For example, the vertical beta function in the undulator should be optimized for a long beam lifetime because a long lifetime of the stored beam means a low loss rate of electrons.

\section{LATTICE PARAMETERS FOR HIGH BRILLIANT UNDULATOR RADIATION}

\section{A. Betatron function in straight sections}

Fundamental storage ring parameters such as low emittance, low emittance coupling and low energy spread are essential to reach high brilliance undulator radiation. The ultimate objective in storage ring design is to obtain high brilliance of SR [76] and therefore optimal betatron functions with zero dispersion should be provided along undulators $[77,78]$. The average brilliance for zero energy spread is given by

$$
B_{r 0}=\frac{F_{n}}{4 \pi^{2} \sum_{x} \sum_{x \prime} \sum_{y} \sum_{y \prime}}
$$

In this equation, $\Sigma_{x, y} / \Sigma_{x^{\prime}, y^{\prime}}$ is the source size/divergence and $F_{n}$ is the on-axis photon flux for the $n$th harmonic given by

$$
F_{n}=1.431 \times 10^{14} I_{b} N K^{2} \xi\left[J_{(n-1) / 2}\left(K^{2} \xi / 4\right)-J_{(n+1) / 2}\left(K^{2} \xi / 4\right)\right]^{2} \text { (photons/s in } 0.1 \% \text { b.w.) }
$$

where $I_{b}$ is the beam current, $K$ the undulator deflection parameter, $N$ the number of periods and $\xi=n /\left(1+K^{2} / 2\right)$. The average brilliance can be expressed by

$$
B_{r 0}=\frac{F_{n}}{4 \pi^{2} \sqrt{\varepsilon_{r}^{2}+\varepsilon_{x}^{2}+\varepsilon_{r} \varepsilon_{x}\left(\zeta_{x}+\zeta_{x}^{-1}\right)} \sqrt{\varepsilon_{r}^{2}+\varepsilon_{y}^{2}+\varepsilon_{r} \varepsilon_{y}\left(\zeta_{y}+\zeta_{y}^{-1}\right)}},
$$

where $\varepsilon_{x} / \varepsilon_{y}$ is the horizontal/vertical electron beam emittance, $\varepsilon_{r}(=\lambda / 4 \pi)$ is the diffraction limited emittance of radiation for a purely Gaussian beam, $\zeta_{x, y}=2 \pi \beta_{x, y} / L_{u}, \lambda$ is the radiation wavelength, $L_{u}$ is the undulator length, and $\beta_{x} / \beta_{y}$ is the horizontal/vertical betatron function, respectively. The maximum brilliance is reached for $\beta_{x, y}=L_{u} / 2 \pi$ :

$$
B_{r 0 \max }=\frac{F_{n}}{4 \pi^{2}\left(\varepsilon_{r}+\varepsilon_{x}\right)\left(\varepsilon_{r}+\varepsilon_{y}\right)} .
$$


The optimum vertical betatron function is $\beta_{y}=L_{u} / 2$ in the middle of the straight section which exhibits the minimum variation along the undulator, thus providing the longest beam lifetime for a given undulator length $[79,80]$. Such a criterion may be less critical for top-up injection in which the beam lifetime issue is less of a concern, but a reduced beam lifetime due to a small undulator gap may cause some risks for radiation damage of PMs. Figure 10 shows an example of the dependence of the relative brilliance, $B_{r 0}$ of Eq. (9), at a wavelength of $0.1 \mathrm{~nm}$ on the horizontal betatron function for different beam emittances. As shown, the brilliance depends very sensitively on the horizontal betatron function and reaches a maximum for $\beta_{x}=L_{u} / 2 \pi$ while the emittance of electrons is low. If the emittance of the photon and electron beam is comparable, matching of the electron-photon phase space can be achieved when the horizontal betatron function at the center of the straight section is $\beta_{x}=L_{u} / 2 \pi$. Thus, the combination of electron and photon emittance can be minimized to reach a maximum SR brilliance [77,78]. As a result, $\beta_{x}=L_{u} / 2 \pi$ and $\beta_{y}=L_{u} / 2$ are recommended for undulators to get high brilliance with minimum beam loss.

\section{B. Dispersion function at the straight section}

In the lattice design of a storage ring, low emittance can be achieved through (1) a multibend lattice, such as MAX-IV or Sirius [81,82], (2) enhancement of radiation damping, such as NSLS-II, MAX-IV or Sirius [81-83], and (3) lowering the dispersion in bending magnets by introducing finite dispersion in straight sections (nonachromatic lattice) [84], such as SPring8, SLS, TPS or many present third generation storage rings. However, the emittance

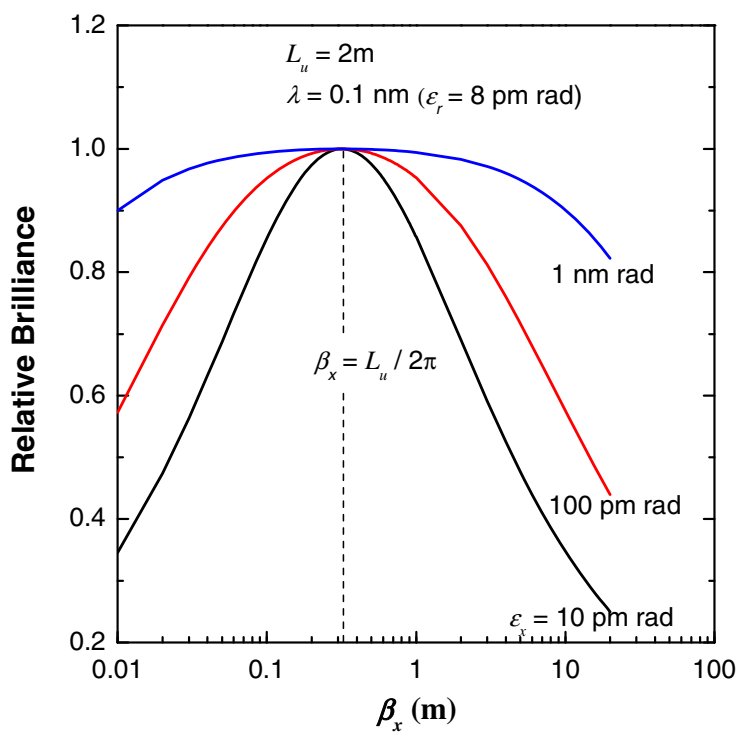

FIG. 10. Dependence of the relative brilliance on the horizontal betatron function for different electron emittances. reduction with finite dispersion in straight sections does not always result in a higher brilliance for undulator radiation. In the case of a low emittance source, finite dispersion can cause a significant increase of the effective emittance as seen by the SR users. Therefore, in a very low emittance storage ring the dispersion function should vanish in the straight sections to avoid brilliance degradation due to a finite dispersion.

The conceptual method to reduce the beam emittance in a storage ring is to increase synchrotron radiation damping while avoiding radiation excitation. If an undulator is placed in a nondispersion-free straight section, then an increase of emittance can occur due to the finite dispersion in combination with the undulator magnetic field. Therefore, an emittance reduction can be expected from a radiation damping effect by placing undulators in a zerodispersion straight section. Especially, damping wigglers or high field IVU/CPMUs and SCUs can be employed in the zero dispersion section to enhance damping and thus reduce the beam emittance. As a result, enhanced SR brilliance can be expected in all undulator beam lines.

\section{Energy spread effect on the undulator brilliance}

Future storage rings are proposed to reach subnanometer emittances. Furthermore, a large number of undulator periods is thought to increase the brilliance of radiation from an undulator, which, however, is not always a practical approach in a low emittance ring with finite energy spread. In contrast to the electron emittance, a typical value of the energy spread for most synchrotron radiation storage rings is of the order of $10^{-3}$ and cannot be reduced significantly. The practical brilliance including effects from a finite energy spread can therefore be approximated as

$$
B_{r}=f_{n, N} B_{r o},
$$

where $f_{n, N}$ is the degradation factor derived from the energy spread in an $N$-period undulator for the $n$th harmonic [85] as shown in the following equation:

$f_{n, N}=\left[\frac{\sigma_{\omega}}{\omega}\right]_{n, N} /\left(\frac{\Sigma_{\omega}}{\omega}\right)=1 / \sqrt{1+\left[5 n N\left(\frac{\sigma_{\gamma}}{\gamma}\right)\right]^{2}}$.

In this equation, $\left[\sigma_{\omega} / \omega\right]_{n, N}$ is the natural rms spectral width of the undulator radiation, $\Sigma_{\omega} / \omega$ is the rms spectral width including a finite energy spread, and $\sigma_{\gamma} / \gamma$ is the energy spread.

Figure 11 shows the dependence of undulator brilliance, $B_{r}$ of Eq. (13), on the number of periods under the assumption of zero emittance and an energy spread of $10^{-3}$. The undulator is assumed to be a standard undulator with $K=2$. One can see that the brilliance becomes saturated for many periods, and the brilliance of higher 


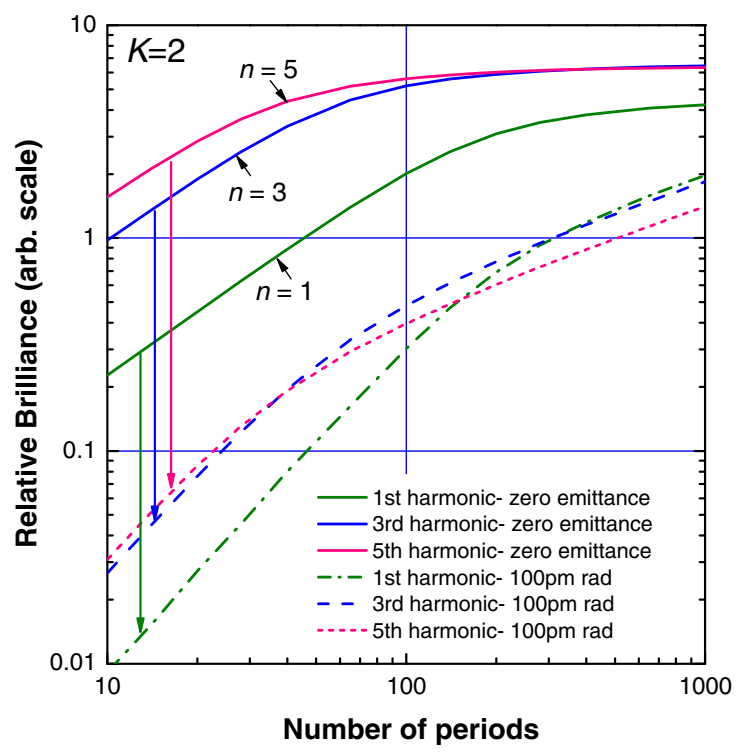

FIG. 11. Dependence of the relative average brilliance on the number of undulator periods for zero emittance or a finite emittance of $100 \mathrm{pm}$ rad and an energy spread of $10^{-3}$. The values for finite emittances have been obtained from SPECTRA [86]. The parameters for the calculation were $E_{\mathrm{GEV}}=3 \mathrm{GeV}$, $\beta_{x}=5.3 \mathrm{~m}, \beta_{y}=1.7 \mathrm{~m}$, a coupling constant of 0.01 and an energy spread of $10^{-3}$.

harmonic reaches a plateau even at smaller numbers of periods. Therefore, the utilization of a long undulator at higher harmonics may not be very effective. A maximum length of an undulator should be adjusted to the storage ring parameters. In Fig. 11, the undulator brilliances in a finite emittance case of $100 \mathrm{pm}$ rad are calculated with the code SPECTRA [86]. The brilliance can be degraded by 1 order of magnitude compared to the zero-emittance case.

\section{CONCLUSION}

Development of short period IVUs/CPMUs is a recent trend for $\mathrm{x}$-ray sources. The IVU technologies are mature and the remaining challenge in the development is therefore concentrated on phase error issues. For a CPMU, most technologies are extended from IVU designs, and therefore, the performance is proven and related technologies are developing. A CPMU has a higher thermal resistance compared to a SCU, and a smaller gap may be allowed with some risks of radiation damage. CPMUs can replace IVUs in the near future to become the preferred $\mathrm{X}$-ray sources in storage rings and XFEL facilities until SCU technologies mature. A small temperature variation in magnet arrays is required to produce low phase errors and technologies for temperature stabilization become the main challenges. A low emittance of a storage ring is essential for a highly brilliant radiation. To satisfy the requirement of high brilliance at minimum cost, the length of an IVU or CPMU should be optimized, together with optimal betatron functions and zero dispersion in straight sections.

\section{ACKNOWLEDGMENTS}

Ministry of Science and Technology, Taiwan supported this research under Contract of Taiwan Photon Source Project. The author would like to thank Dr. J. Chavanne (ESRF), Dr. M. E. Couprie (SOLEIL), Dr. J. Bahrdt (HZB), Dr. S. Milward (DLS), Dr. H. Tanaka (SPring-8) and Dr. H. Wiedemann (Stanford University) for valuable discussions, NEOMAX ENGINEERING and VACUUMSCHMELZE for product information.

[1] H. Hsieh, S. Krinsky, A. Luccio, C. Pellegrini, and A. Steenbergen, Wiggler, undulator and free electron laser radiation sources development at the national synchrotron light source, Nucl. Instrum. Methods Phys. Res. 208, 79 (1983).

[2] W. Gudat, J. Pflüger, J. Chatzipetros, and W. Peatman, An undulator/multipole wiggler for the BESSY storage ring, Nucl. Instrum. Methods Phys. Res., Sect. A 246, 50 (1986).

[3] S. Yamamoto, T. Shioya, M. Hara, H. Kitamura, X. W. Zhang, T. Mochizuki, H. Sugiyama, and M. Ando, Construction of an in-vacuum type undulator for production of undulator $\mathrm{x}$ rays in the $5-25 \mathrm{keV}$ region, Rev. Sci. Instrum. 63, 400 (1992).

[4] H. Kitamura, Insertion devices for third-generation light sources, Rev. Sci. Instrum. 66, 2007 (1995).

[5] J. Chavanne, C. Penel, B. Plan, and F. Revol, In-vacuum undulators at ESRF, in Proceedings of the 2003 Particle Accelerator Conference, Portland, OR (IEEE, New York, 2003), p. 253.

[6] J. Campmany, D. Bertwistle, J. Marcos, Z. Martí, V. Massana, F. Becheri, and D. Einfeld, A general view of IDs to be installed at ALBA on day one, in Proceedings of the 10th European Particle Accelerator Conference, Edinburgh, Scotland, 2006 (EPS-AG, Edinburgh, Scotland, 2006), p. 3598.

[7] G. Ingold, M. Boege, W. Bulgheroni, A. Keller, J. Krempaski, C. Schulze-Briese, L. Schulz, T. Schmidt, D. Zimoch, T. Hara, T. Tanaka, and H. Kitamura, Performance of small-gap undulators at the SLS intermediate energy storage ring, AIP Conf. Proc. 879, 388 (2007).

[8] E. C. Longhi, R. Bartolini1, R. Fielder, I. Martin, J. C. Schouten, B. Singh, and J. Adams, First year's experience of DIAMOND insertion devices, in Proceedings of the 11th European Particle Accelerator Conference, Genoa, 2008 (EPS-AG, Genoa, Italy, 2008), p. 2285.

[9] J.-C. Huang, L.-H. Wu, C.-K. Yang, C.-K. Chuan, T.-Y. Chung, and C.-S. Hwang, Performance of a NSRRC invacuum undulator, IEEE Trans. Appl. Supercond. 24, 0503704 (2014).

[10] T. Tanabe, P. Cappadoro, T. Corwin, H. Fernandes, D. A. Harder, Y. Hidaka, C. Kitegi, M. Musardo, and J. Rank, Insertion devices at the national synchrotron light sourceII, Synchrotron Radiat. News 28, 39 (2015). 
[11] R. P. Walker, Phase errors and their effect on undulator radiation properties, Phys. Rev. ST Accel. Beams 16, 010704 (2013).

[12] M. Yabashi, H. Tanaka, and T. Ishikawa, Overview of the SACLA facility, J. Synchrotron Radiat. 22, 477 (2015).

[13] SwissFEL CDR, Paul Scherrer Institut, Villigen, Switzerland, Report No. 10-04.

[14] H. D. Nuhn, R. C. Field, S. Mao, Y. Levashov, M. Santana, J. N. Welch, and Z. Wolf, Undulator radiation damage experience at LCLS, in Proceedings FEL'14, Basel, Switzerland (2014), p. 127.

[15] T. Bizen, R. Kinjo, T. Hasegawa, A. Kagamihata, Y. Kida, T. Seike, T. Watanabe, T. Hara, T. Itoga, Y. Asano, and T. Tanaka, Radiation-induced magnetization reversal causing a large flux loss in undulator permanent magnets, Sci. Rep. 6, 37937 (2016).

[16] K. Bane and G. Stupakov, Roughness tolerances in the undulator vacuum chamber of LCLS-II, in Proceedings of LINAC'14, Geneva, Switzerland (2014), p. 708.

[17] L. R. Elias, W. M. Fairbank, J. M. J. Madey, H. A. Schwettman, and T. I. Smith, Observation of Stimulated Emission of Radiation by Relativistic Electrons in a Spatially Periodic Transverse Magnetic Field, Phys. Rev. Lett. 36, 717 (1976).

[18] M. Bazin, Y. Farge, M. Lemonnier, J. Perot, and Y. Petroff, Design of an undulator for A.C.O. and its possible use as free electron laser, Nucl. Instrum. Methods Phys. Res. Sect. A 172, 61 (1980).

[19] H. Winick, G. Brown, K. Halbach, and J. Harris, Wiggler and undulator magnets, Phys. Today 34, 50 (1981).

[20] E. Gluskin, Development and performance of superconducting undulators at the advanced photon source, Synchrotron Radiat. News 28, 4 (2015).

[21] S. Casalbuoni, A. Cecilia, S. Gerstl, N. Glamann, A. W. Grau, T. Holubek, C. Meuter, D. S. deJauregui, R. Voutta, C. Boffo, Th. Gerhard, M. Turenne, and W. Walter, Characterization and long term operation of a novel superconducting undulator with $15 \mathrm{~mm}$ period length in a synchrotron light source, Phys. Rev. ST Accel. Beams 19, 110702 (2016).

[22] T. Hara, T. Tanaka, H. Kitamura, T. Bizen, X. Maréchal, T. Seike, T. Kohda, and Y. Matsuura, Cryogenic permanent magnet undulators, Phys. Rev. ST Accel. Beams 7, 050702 (2004).

[23] T. Tanaka, T. Hara, T. Bizen, T. Seike, R. Tsuru, X. Maréchal, H. Hirano, M. Morita, H. Teshima, S. Nariki, N. Sakai, I. Hirabayashi, M. Murakami, and H. Kitamura, Development of cryogenic permanent undulators operating around liquid nitrogen temperature, New J. Phys. 8, 287 (2006).

[24] T. Tanaka, R. Tsuru, T. Nakajima, and H. Kitamura, Magnetic characterization for cryogenic permanentmagnet undulators: a first result, J. Synchrotron Radiat. 14, 416 (2007).

[25] C. Benabderrahmane, P. Berteaud, M. Valléau, C. Kitegi, K. Tavakoli, N. Béchu, A. Mary, J. M. Filhol, and M. E. Couprie, $\mathrm{Nd}_{2} \mathrm{Fe}_{14} \mathrm{~B}$ and $\mathrm{Pr}_{2} \mathrm{Fe}_{14} \mathrm{~B}$ magnets characterisation and modelling for cryogenic permanent magnet undulator applications, Nucl. Instrum. Methods Phys. Res., Sect. A 669, 1 (2012).
[26] F. H. O'Shea, G. Marcus, J. B. Rosenzweig, M. Scheer, J. Bahrdt, R. Weingartner, A. Gaupp, and F. Grüner, Short period, high field cryogenic undulator for extreme performance X-ray free electron lasers, Phys. Rev. ST Accel. Beams 13, 070702 (2010).

[27] F. Holy, A. R. Maier, B. Zeitler, R. Weingartner, S. Raith, N. Kajumba, M. E. Ghazaly, W. Lauth, D. Krambrich, A. Gaupp, M. Scheer, J. Bahrdt, and F. Grüner, First spectral measurements of a cryogenic high-field short-period undulator, Phys. Rev. ST Accel. Beams 17, 050704 (2014).

[28] J. Chavanne, M. Hahn, R. Kersevan, C. Kitegi, C. Penel, and F. Revol, Construction of a cryogenic permanent magnet Undulator at the ESRF, in Proceedings of the 11th European Particle Accelerator Conference, Genoa, 2008 (Ref. [8]), p. 2243.

[29] J. Chavanne, G. Le Bec, C. Penel, and F. Revol, First operational experience with a cryogenic permanent magnet Undulator at the ESRF, in Proceedings of the 23rd Particle Accelerator Conference, Vancouver, Canada, 2009 (IEEE, Piscataway, NJ, 2009), p. 2414.

[30] J. Chavanne, G. Le Bec, and C. Penel, Cryogenic permanent magnet undulators, Synchrotron Radiat. News 24, 10 (2011).

[31] C. Benabderrahmane et al., Development and operation of a $\operatorname{Pr}_{2} \mathrm{Fe}_{14} \mathrm{~B}$ based cryogenic permanent magnet undulator for a high spatial resolution X-ray beam line, Phys. Rev. ST Accel. Beams 20, 033201 (2017).

[32] C. W. Ostenfeld and M. Pedersen, Cryogenic in-vacuum undulator at danfysik, in Proceedings of the International Particle Accelerator Conference, Kyoto, Japan (ICR, Kyoto, 2010), p. 3093.

[33] M. Calvi, Th. Schmidt, A. Anghel, A. Cervellino, S. J. Leake, P. R. Willmott, and T. Tanaka, Commissioning results of the U14 cryogenic undulator at SLS, J. Physics Conf. Ser. 425, 032017 (2013).

[34] J. Chavanne, C. Benabderrahmane, G. Le Bec, and C. Penel, Recent developments in insertion devices at the ESRF: Working toward diffraction-limited storage rings, Synchrotron Radiat. News 28, 15 (2015).

[35] H. Kitamura, T. Hara, T. Tanaka, T. Bizen, X. Maréchal, and T. Seike, Design criteria and technology challenges for the undulators of the future, in Proceedings of the 9th European Particle Accelerator Conference, Lucerne, 2004 (EPS-AG, Lucerne, 2004), p. 59.

[36] J. Chavanne and G. Le Bec, Prospects for the use of permanent magnets in future accelerator facilities, in Proceedings of IPAC'14, Dresden, Germany (2014), p. 968.

[37] T. Bizen, Y. Asano, T. Hara, X. Maréchal, T. Seike, T. Tanaka, H. S. Lee, D. E. Kim, C. W. Chung, and H. Kitamura, Baking effect for $\mathrm{NdFeB}$ magnets against demagnetization induced by high-energy electrons, Nucl. Instrum. Methods Phys. Res., Sect. A 515, 850 (2003).

[38] Hitachi Metals Co., U.S. Patent Publication No. US2008/ 0286585 A1, 2008.

[39] F. J. Börgermann, C. Brombacher, and K. Üstüner, Properties, options and limitations of PrFeB-magnets for cryogenic undulator, in Proceedings of IPAC'14, Dresden, Germany (2014), p. 1238. 
[40] H. Kitamura, in Proceedings of the 6th Meeting on Ultrahigh Vacuum Techniques for Accelerators and Storage Rings (KEK Report No. 87-8, 1987), p. 147.

[41] T. Bizen, X. Maréchal, T. Seike, H. Kitamura, T. Hara, T. Tanaka, Y. Asano, D. E. Kim, and H. S. Lee, Radiation damage in permanent magnets for ID, Radiation Measurements 41, S260 (2006).

[42] A. Baron, T. Tanaka, K. Soutome, M. Takao, T. Nakamura, K. Kobayashi, T. Fujita, S. Takahashi, H. Aoyagi, Y. Shimosaki, T. Seike, H. Uchiyama, D. Ishikawa, T. H. Chuang, H. Kimura, H. Tanaka, H. Kitamura, and T. Ishikawa, Toward operation of series IDs at BL43LXU of SPring-8, AIP Conf. Proc. 1741, 020033 (2016).

[43] R. Reiser, S. Zelenika, G. Ingold, A. Keller, L. Schulz, T. Hara, and H. Kitamura, The flexible taper transitions for an in-vacuum undulator, in Proceedings of MEDSI'02, Chicago, USA (2002), p. 323.

[44] H. Kitamura, Design criteria and technology challenges for the undulators of the future, Proceedings of the 9th European Particle Accelerator Conference, Lucerne, 2004 (Ref. [35]).

[45] J. Bahrdt and Y. Ivanyushenkov, Short period undulators for storage rings and free electron lasers, J. Phys. Conf. Ser. 425, 032001 (2013).

[46] E. C. Longhi, A. Miller, E. Rial, A. Rose, J. Schouten, C. Thompson, A. Thomson, J. Williams, and C. Monroe, A new cooling system for cryocooled permanent magnet undulators at diamond light source, in Proceedings of IPAC'14, Dresden, Germany (2014) 2047.

[47] J. Bahrdt and C. Kuhn, Cryogenic permanent magnet undulator development at HZB/BESSY II, Synchrotron Radiat. News 28, 9 (2015).

[48] J. C. Huang, H. Kitamura, C. Y. Kuo, C. K. Yang, C. S. Chang, Y. T. Yu, and C. S. Hwang, Design of a magnetic circuit for a cryogenic undulator in Taiwan photon source, AIP Conf. Proc. 1741, 020016 (2016).

[49] M. Valléau et al., Development of cryogenic undulators with PrFeB magnets at SOLEIL, AIP Conf. Proc. 1741, 020024 (2016).

[50] K. Uestuener, M. Katter, R. Blank, D. Benedikt, J. Bahrdt, A. Gaupp, B. Klemke, F. Grüner, and R. Weingartner, Sintered (Pr,Nd)-Fe-B permanent magnets with $(\mathrm{BH})_{\max }$ of $520 \mathrm{~kJ} / \mathrm{m}^{3}$ at $85 \mathrm{~K}$ for cryogenic applications, in Proceedings of the 20th Conference on Rare Earth Permanent Magnets, Crete, Greece (2008), p. 85.

[51] M. E. Couprie, F. Briquez, G. Sharma, C. Benabderrahmane, F Marteau, O. Marcouillé, P. Berteaud, T. El Ajjouri, J. Vétéran, L. Chapuis, and M. Valléau, Cryogenic undulators, Proc. SPIE Int. Soc. Opt. Eng. 9512, 951204 (2015).

[52] R. Kinjo, T. Bizen, and T. Tanaka, Undulator development for SPring-8-II, Synchrotron Radiat. News 28, 45 (2015).

[53] J. C. Huang, H. Kitamura, C. H. Chang, C. H. Chang, T. Y. Chung, C. S. Hwang, C. K. Yang, and Y. T. Yu, Challenge of in-vacuum and cryogenic permanent magnet undulator technologies, in 7th International Particle Accelerator Conference, IPAC-2016, Busan, Korea, 2016 (JACoW, Geneva, 2016), p. 1080.

[54] C. Kitegi, Development of a cryogenic permanent magnet undulator at the ESRF, Ph.D. thesis, Universite JosephFourier- Grenoble I, 2008.
[55] M. Coupier, Undulator technologies for future FEL facilities/Storage rings, in Proceedings of the 4th International Particle Accelerator Conference, IPAC-2013, Shanghai, China, 2013 (JACoW, Shanghai, China, 2013).

[56] C. K. Yang, C. H. Chang, S. D. Chen, Y. Y. Lin, and C. S. Hwang, Field measurement system in vacuum for a cryogenic permanent-magnet undulator at NSRRC, IEEE Trans. Appl. Supercond. 26, 9500804 (2016).

[57] C. Kuhn, H. J. Baecker, J. Bahrdt, A. Gaupp, and B. Schulz, in Proceedings of the 4th International Particle Accelerator Conference, IPAC-2013, Shanghai, China, 2013 (Ref. [55]), p. 2126.

[58] J. Safranek, C. Limborg, A. Terebilo, K. I. Blomqvist, P. Elleaume, and Y. Nosochkov, Nonlinear dynamics in a SPEAR wiggler, Phys. Rev. ST Accel. Beams 5, 010701 (2002).

[59] T. Bizen, T. Hara, X. Maréchal, T. Seike, T. Tanaka, and H. Kitamura, Development of in-vacuum revolver undulator, AIP Conf. Proc. 705, 175 (2004).

[60] R. Kinjo, T. Tanaka, T. Seike, A. Kagamihata, and S. Yamamoto, Development of a magnetic system to cancel the attractive force toward structural reform of undulators, in Proceedings of FEL'14, Basel, Switzerland (2014), p. 75 .

[61] O. Marcouille, N. Bechu, P. Berteaud, P. Brunelle, L. Chapuis, C. Herbeaux, A. Lestrade, J. L. Marlats, A. Mary, M. Massal, A. Nadji, K. Tavakoli, M. Valleau, J. Veteran, M. E. Couprie, and J. M. Filhol, In vacuum permanent magnet wiggler optimized for the production of hard x rays, Phys. Rev. ST Accel. Beams 16, 050702 (2013).

[62] N. Strelnikov, E. Trakhtenberg, I. Vasserman, J. Xu, and E. Gluskin, Vertically polarizing undulator with the dynamic compensation of magnetic forces for the next generation of light sources, Rev. Sci. Instrum. 85, 113303 (2014).

[63] T. Tanaka, T. Seike, A. Kagamihata, T. Schmidt, A. Anghel, M. Brügger, W. Bulgheroni, B. Jakob, and H. Kitamura, In situ correction of field errors induced by temperature gradient in cryogenic undulators, Phys. Rev. ST Accel. Beams 12, 120702 (2009).

[64] T. Hara, T. Tanaka, T. Tanabe, X. Maréchal, H. Kitamura, P. Elleaume, B. Morrison, J. Chavanne, P. Van Vaerenbergh, and D. Schmidt, SPring-8 in-vacuum undulator beam test at the ESRF, J. Synchrotron Radiat. 5, 406 (1998).

[65] J. C. Huang, H. Kitamura, C. H. Chang, C. H. Chang, and C.S. Hwang, Beam-induced heat load in in-vacuum undulators with a small magnetic gap, Nucl. Instrum. Methods Phys. Res., Sect. A 775, 162 (2015).

[66] K. J. Kim, Angular distribution of undulator power for an arbitrary deflection parameter K, Nucl. Instrum. Methods Phys. Res., Sect. A 246, 67 (1986).

[67] K. Bane and S. Krinsky, Impedance of a small-gap undulator vacuum chamber, in Proceedings of the 15th Particle Accelerator Conference, PAC-1993, Washington, DC, 1993 (IEEE, New York, 1993), p. 3375.

[68] W. Chou and F. Ruggiero, Anomalous skin effect and resistive wall heating, LHC Project Note 2 (SL/AP), 1995.

[69] A. Madur, S. Marks, S. Prestemon, D. Robin, T. Scarvie, R. Schlueter, and C. Steier, Troubleshooting status for the ALS In-vacuum insertion device, in Proceedings of the 
23rd Particle Accelerator Conference, Vancouver, Canada, 2009 (Ref. [29]), p. 333.

[70] M. E. Couprie, Some recent Insertion Device innovations on operating third and fourth generation light sources, ICFA Workshop, Thomas Jefferson National Accelerator Facility, USA, 2012.

[71] M. Tischer, P. Neumann, A. Schöps, and P. Vagin, Refurbishment of radiation-damaged undulators, AIP Conf. Proc. 1741, 020022 (2016).

[72] S. Sasaki, M. Petra, I. B. Vasserman, C. L. Doose, E. R. Moog, and N. V. Mokhov, Radiation damage to advanced photon source undulators, in Proceedings of the $21 \mathrm{st}$ Particle Accelerator Conference, Knoxville, TN, 2005 (IEEE, Piscataway, NJ, 2005), p. 4126.

[73] P. Van Vaerenbergh, J. Chavanne, and P. Elleaume, in Proceedings of the Fifth European Conference on Radiation and Its Effects on Components and Systems, Fontevraud, France (1999), p. 246.

[74] T. Tanaka, Undulator development for the SPring-8 storage ring and XFEL, IDMAX 2010 Workshop, Lund, Sweden, 2010.

[75] T. Bizen, X.-M. Maréchal, T. Seike, H. Kitamura, T. Hara, T. Tanaka, Y. Asano, D. E. Kim, and H. S. Lee, in Proceedings of the 9th European Particle Accelerator Conference, Lucerne, 2004 (EPS-AG, Lucerne, 2004), p. 2092.

[76] M. Bei, M. Borland, Y. Cai, P. Elleaume, R. Gerig, K. Harkay, L. Emery, A. Hutton, R. Hettel, R. Nagaoka, D. Robin, and C. Steier, The potential of an ultimate storage ring for future light sources, Nucl. Instrum. Methods Phys. Res., Sect. A 622, 518 (2010).

[77] Y. Cai, K. Bane, R. Hettel, Y. Nosochkov, M. H. Wang, and M. Borland, Ultimate storage ring based on fourth-order geometric achromats, Phys. Rev. ST Accel. Beams 15, 054002 (2012).
[78] H. Wiedemann, Particle Accelerator Physics (Springer, New York, 2007), p. 784.

[79] H. Kitamura, Recent trends of insertion-device technology for X-ray sources, J. Synchrotron Radiat. 7, 121 (2000).

[80] C. S. Hwang, J. C. Jan, C. S. Chang, S. D. Chen, C. H. Chang, and T. M. Uen, Development trends for insertion devices of future synchrotron light sources, Phys. Rev. ST Accel. Beams 14, 044801 (2011).

[81] S. C. Leemann, A. Andersson, M. Eriksson, L.-J. Lindgren, and E. Wallén, Beam dynamics and expected performance of Sweden's new storage-ring light source: MAX IV, Phys. Rev. ST Accel. Beams 12, 120701 (2009).

[82] L. Liu, N. Milas, A. H. Mukai, X. R. Resende, A. R. D. Rodrigues, and F. H. Sá, A new 5BA low emittance lattice for sirius, in Proceedings of the 4th International Particle Accelerator Conference, IPAC-2013, Shanghai, China, 2013 (Ref. [56]), p. 1874.

[83] S. Ozaki, J. Bengtsson, S. L. Kramer, S. Krinsky, and V. N. Litvinenko, Philosophy for NSLS-II design with subnanometer horizontal emittance, in Proceedings of the 16th IEEE International Pulsed Power Conference, Albuquerque, NM (IEEE, Piscataway, NJ, 2007), p. 77.

[84] H. Tanaka and A. Ando, Minimum effective emittance in synchrotron radiation sources composed of modified Chasman Green lattice, Nucl. Instrum. Methods Phys. Res., Sect. A 369, 312 (1996).

[85] J. C. Huang, H. Kitamura, C. K. Yang, M. S. Chiu, C. H. Chang, and C.S. Hwang, Applicability of a doubleundulator configuration, Nucl. Instrum. Methods Phys. Res., Sect. A 808, 93 (2016).

[86] T. Tanaka and H. Kitamura, SPECTRA: a synchrotron radiation calculation code, J. Synchrotron Radiat. 8, 1221 (2001). 